\title{
EDUCACIÓN E INNOVACIÓN: \\ PILARES DEL DESARROLLO
}

\section{Leonidas Torres Citraro*}

\section{INTRODUCCIÓN}

Las habilidades y aptitudes tienen un impacto importante en las oportunidades de vida de cada individuo. Las habilidades transforman vidas, generan prosperidad y promueven la inclusión social. Sin los conocimientos adecuados, las personas se mantienen al margen de la sociedad, y el progreso tecnológico no se traduce en el crecimiento económico, por lo que las empresas y los países no pueden competir en un mundo globalmente conectado y cada vez más complejo. Para obtener los mejores rendimientos de la inversión, para formar personas con habilidades y aptitudes se requiere de buena información sobre los perfiles ocupacionales que se necesitan y los que se encuentran disponibles en el mercado laboral. También se requiere de políticas que aseguren que las habilidades se van a utilizar efectivamente para generar mejores empleos que conduzcan a una vida mejor.

En cuanto a las oportunidades de vida de cada individuo y el factor decisivo de sus habilidades, las estadísticas y publicaciones de la OECD ("OECD Skills Outlook 2013")1 señalan, por ejemplo, que el salario medio por hora de los trabajadores con calificaciones en el nivel 4 o 5 en lectura y comprensión (aquellos que pueden hacer inferencias complejas y evaluar las pretensiones sutiles o argumentos en textos escritos) es más de un 60\% superior que el de los trabaja-

\footnotetext{
* Ingeniero industrial (1969) de la Universidad de Mackenzie, Sao Paulo, e ingeniero mecanico (1988) de la Universidad Central de Venezuela. Asesor empresarial en las áreas de finanzas, inversiones, mercado de capitales y propiedad intelectual. Profesor del mercado avanzado de Propiedad Intelectual, curso aplicado por la Cámara Venezolana del Medicamento (caveme) y la Universidad Católica Andrés Bello, Caracas, Venezuela. Profesor invitado del posgrado de la Universidad de los Andes (Mérida). Correo-e: leonitor@gmail.com Fecha de recepción: 5 de octubre de 2015. Fecha de aceptación: 15 de octubre de 2015. Para citar en artículo: Torres C., L. Educación e innovación: pilares del desarrollo. Revista La Propiedad Inmaterial n. ${ }^{\circ}$ 20, Universidad Externado de Colombia, julio-diciembre 2015, pp. 85-117. DOI: http://dx.doi.org/10.18601/16571959.n20.05

1. “OECD Skills Outlook 2013”, disponible en: http://skills.oecd.org/skillsoutlook.html
} 
dores con calificaciones en el nivel 1 o por debajo, que son los que pueden -en el mejor de los casos- leer textos relativamente cortos para ubicar una sola pieza de información, que es idéntica a la suministrada en la pregunta, o entender el vocabulario básico. Las personas con bajo nivel de alfabetización tienen más del doble de probabilidades de estar desempleadas.

La revolución tecnológica que se inició en las últimas décadas del siglo xx ha afectado a casi todos los aspectos de la vida, desde la forma en que hablamos con nuestra familia y amigos, a la forma en que compramos, cómo y dónde trabajamos. Servicios de transporte y comunicación más rápidos y más eficientes han facilitado a las personas, bienes, servicios y capitales moverse por el mundo, lo que ha llevado a la globalización de las economías. Los nuevos medios de comunicación y tipos de servicios han cambiado la forma en que se interactúa con los gobiernos, proveedores de servicios y entre sí.

Estas transformaciones sociales y económicas han cambiado la demanda de habilidades. Si bien hay muchos factores responsables de estos cambios, los avances tecnológicos, en particular de las tecnologías de la información y las comunicaciones (TIC), han alterado profundamente lo que se considera que son las "competencias clave de procesamiento de información" que tanto los individuos como las economías y las sociedades necesitan para evolucionar en el siglo XXI.

Con la fabricación y otras tareas de baja calificación en el sector de servicios cada vez más automatizadas, la necesidad de habilidades repetitivas y de rutina está disminuyendo, mientras que la demanda de capacidades de procesamiento de información y otras habilidades cognitivas e interpersonales de alto nivel es cada vez mayor. Además de dominar habilidades específicas de su profesión, los trabajadores en el siglo Xxi también deben tener conocimientos sobre procesamiento de información, buen nivel de lectura, cálculo y resolución de problemas, y habilidades genéricas, como la comunicación interpersonal, la autogestión y la capacidad para aprender, para ayudarles a capear la incertidumbre de un mercado de trabajo que cambia rápidamente.

La mejora de la oferta de capacidades es solo la mitad de la historia: la escasez de habilidades coexiste con altas tasas de desempleo, por lo que se debe hacer mejor uso de las capacidades existentes. Existe un creciente interés entre los responsables políticos no solo en la creación de los incentivos adecuados para que las empresas y los particulares inviertan en el desarrollo de habilidades, sino también para garantizar que las economías utilicen plenamente las habilidades disponibles.

La tecnología ha jugado un papel central en la globalización de los mercados, principalmente al aumentar el alcance y la velocidad de la comunicación y ayudando a reducir los costos, los cuales han facilitado el flujo de bienes, capital, personas e información a través de las fronteras. A su vez, la globalización ha tenido un fuerte impacto en las oportunidades de trabajo y la demanda de competencias en los mercados de trabajo locales. A fin de cuentas, el comercio desempeña un 
papel importante en la creación de mejores puestos de trabajo, el aumento de los salarios en los países ricos y pobres, y la mejora de las condiciones de trabajo; pero estos beneficios potenciales no se obtienen automáticamente.

La globalización también ha llevado a la externalización (outsourcing) de la producción. Puestos de trabajo poco calificados se van cada vez más a la externalización, es decir a otro lugar con salarios y ubicaciones de bajo costo en los países menos desarrollados. La externalización se está extendiendo cada vez más de la manufactura a las industrias intensivas en tecnología, incluidos los servicios. La deslocalización de puestos de trabajo a países con mano de obra moderadamente educada y con salarios comparativamente más bajos se menciona como una posible razón de la disminución de puestos de trabajo de nivel medio en las economías más avanzadas.

El tema de cómo se relacionan la educación, la innovación y el desarrollo ha dado lugar a innumerables investigaciones y publicaciones por parte de los más prestigiosos economistas, sociólogos y expertos de la academia, las universidades y los organismos internacionales. Son muy variados los criterios, opiniones y mediciones de esta relación, pero en lo que todos coinciden es en que sin educación e innovación no hay desarrollo.

La innovación en el siglo xxi deberá evolucionar para enfrentar colosales fuerzas disruptivas de naturaleza económica, social y política, que son las que van a modelar y definir la civilización en el siglo xxi; entre las más relevantes cabe mencionar la creciente urbanización, el cambio de la estructura demográfica, la profundización de la globalización, la contaminación y la alarmante desigualdad social.

El enfoque que hasta el presente le hemos dado a la labor de ciencia, tecnología e innovación no servirá para resolver los problemas básicos del género humano, que si los pudiéramos resumir en una línea diríamos que son: alimentación, agua, energía, salud, vivienda y educación, todos ellos con la premisa de ser solventados en el corto y mediano plazo para que podamos sobrevivir como especie. Son problemas de escala global, sobre todo ante la expectativa de que para el año 2050 la población del planeta habrá superado los 9.500 millones de seres ${ }^{2}$. Es necesario enfatizar que dichos problemas han sido abordados con timidez, obteniendo resultados frágiles y en algunos casos con probabilidades de retroceso.

El paradigma tecnológico predominante está experimentando cambios de tal magnitud que han sido calificados como una nueva revolución tecnológica. Esta se basa en la convergencia de las trayectorias en curso en las áreas de la nanotecnología, la biotecnología y las tecnologías de la información y las comunicaciones (TIC). Cada una de estas áreas avanza rápidamente, pero lo más importante 
es la tendencia a su combinación. La convergencia de estas tecnologías nos está llevando a soluciones insospechadas hace pocos años.

La conjugación de los avances en áreas como la nanotecnología, bioingeniería, nuevos materiales, algoritmos avanzados y machine learning con seguridad transformará las estructuras económicas, políticas, institucionales y sociales, con una amplitud global y una velocidad mayor que la de las anteriores revoluciones. Esas revoluciones generaron enormes aumentos en la capacidad productiva: nos referimos a la máquina de vapor, la electricidad, el ferrocarril, la metalúrgica, la producción en masa y otras, las cuales dieron lugar a incrementos sostenidos del ingreso per cápita y la calidad de vida de gran parte de la población de los países que lideraron el proceso, entre los que no estaban incluidos los de América Latina, figurando solo como simples usuarios y nunca como generadores de esas tecnologías.

Nos preocupa, a los habitantes de los países de América Latina, que a pesar de un esfuerzo de décadas y de cuantiosas inversiones en educación, seguimos sin atisbar la vanguardia de países y empresas que trabajan en las fronteras del conocimiento. Nos ocurre algo parecido al piloto que decide acelerar su vehículo a $100 \mathrm{~km} /$ hora para alcanzar a los punteros, pero estos ya han aumentado a 200 $\mathrm{km} /$ hora y se alejan aún más del decidido piloto.

\section{Diagnóstico de la Situación aCtual}

Para saber cuán acertada es la sospecha de que nos estamos alejando o acercando a los punteros es necesario conocer algunos indicadores que nos permitan elaborar un diagnóstico de la situación.

\section{i. Programa Internacional de Evaluación de Estudiantes (pisa)}

El Programa Internacional de Evaluación de Estudiantes (PISA, por sus siglas en inglés) ${ }^{3}$ es una iniciativa de la Organization for Economic Co-operation and Development (OECD), que tiene por objeto evaluar hasta qué punto los alumnos cercanos al final de la educación secundaria han adquirido el saber y las habilidades necesarias para su plena participación en la sociedad del conocimiento. Las pruebas de PISA son aplicadas cada tres años para examinar el rendimiento de alumnos de 15 años en áreas temáticas clave como lectura, matemática y ciencias.

El estudio PISA 2012 se centró en las matemáticas, la lectura, la ciencia y áreas menores de resolución de problemas. Por primera vez, PISA 2012 también incluyó una evaluación de la educación financiera de los estudiantes participantes. 
Los países participantes en PISA 2012 fueron 65: 34 países miembros de la oCDE (estos son todos los países de Europa más Estados Unidos, Canadá, Australia, Nueva Zelanda, Japón, Corea del Sur e Israel) y 31 países asociados (entre ellos China, Rusia y ocho de América Latina), que en conjunto representan más del $80 \%$ de la economía mundial.

Los estudiantes participantes fueron alrededor de 510.000, entre 15 y 16 años.

Por América Latina participaron Chile, México, Uruguay, Costa Rica, Brasil, Argentina, Colombia y Perú, es decir, 8 países. De los 65 países que participaron, los de América Latina ocuparon los 15 últimos lugares, junto con Malasia, Montenegro, Albania, Túnez, Jordán, Qatar e Indonesia.

\section{Global Innovation Index (Gi)}

Esta es una iniciativa del INSEAD (escuela de negocios) conjuntamente con la ompr y Cornell University, con el propósito de clasificar a los países que ofrezcan mejores condiciones para la innovación y la creatividad ${ }^{4}$.

Este Índice explora el poder de transformación de la innovación, identifica las condiciones y cualidades que permiten la innovación en el desarrollo y pone de relieve el papel que esta puede desempeñar en un país.

El GII es el resultado de la aplicación de un modelo que consta de dos subíndices, uno de entrada (inputs), conformado por cinco pilares: (1) instituciones, (2) capital humano e I\&D, (3) infraestructura, (4) sofisticación del mercado y (5) sofisticación de negocios; y otro de resultados (outputs), conformado por dos pilares: (6) conocimiento y tecnología y (7) productos creativos. En total se aplican 81 indicadores para la clasificación final, en la que participaron 143 países y economías.

Los mejores puestos de América Latina los ocupan Chile (46), Panamá (52), Costa Rica (57), Brasil (61), México (66), Colombia (68) y Argentina (70), y luego vienen doce países de la región después del puesto 80 .

\section{3. "The Global Information Technology Report 20i5", Que incluye el Networked Readiness Index (nri) elaborado por el World Economic Forum (Wef)}

En el mencionado reporte de la $\operatorname{WEF}^{5}$ se hace hincapié en el impacto que tienen las TiC en el desarrollo y crecimiento del pIB per cápita; a tal efecto se incluye un gráfico donde se evidencia esa relación: 


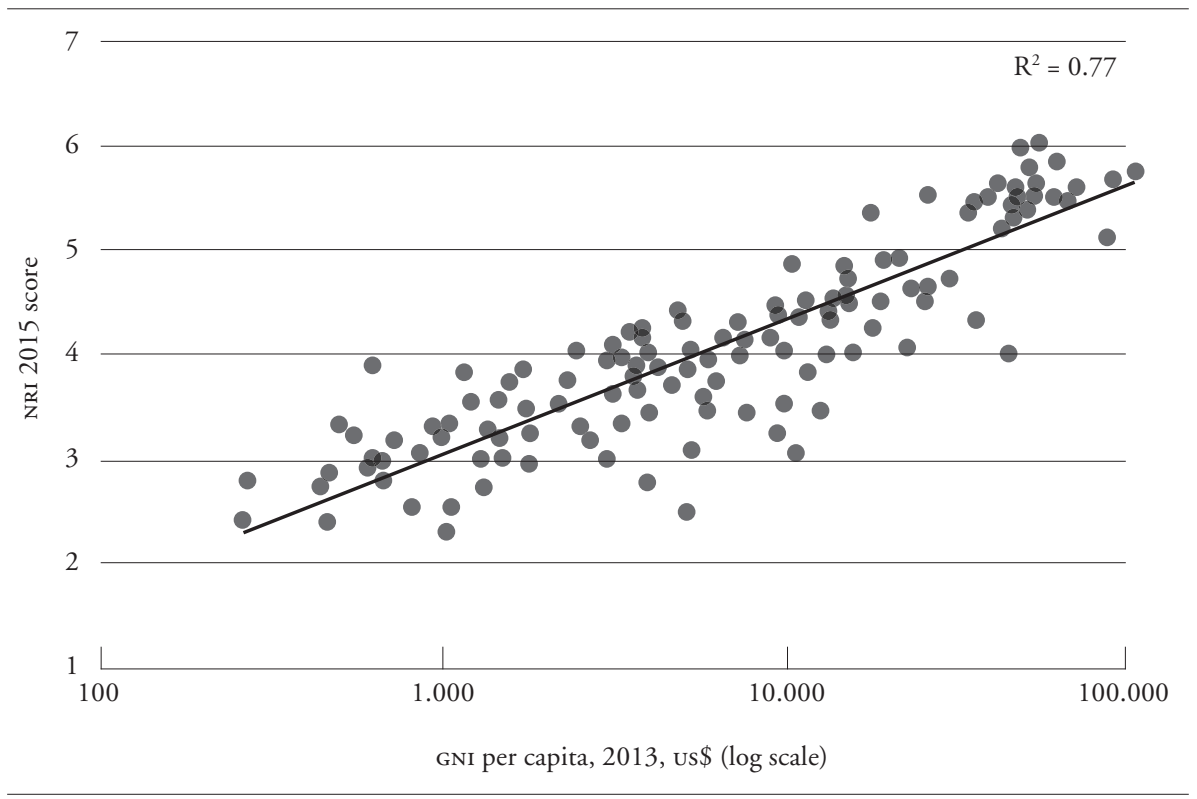

Como era de esperar, las economías avanzadas aprovechan mejor las Tic que los países en desarrollo. Las economías con altos ingresos dominan el NRI (Índice de Disponibilidad de Red), ocupando los 31 primeros lugares en el ranking NRI. El desempeño de los países en el NRI en buena parte refleja su posición en la escala del desarrollo, es decir, un nivel más alto del ingreso per cápita se asocia típicamente con un NRI superior, por eso 44 de los 50 países de altos ingresos están incluidos en el top 50 del ranking NRI.

\section{Perspectiva histórica}

$\mathrm{Al}$ analizar los indicadores presentados y las conclusiones de distintos frentes de investigación sobre la precaria situación de la educación en América Latina, la pregunta que surge es: ¿siempre estuvimos en desventaja?

Una buena aproximación a nuestro pasado -en el tema de la educación y el desarrollo- la obtenemos del artículo "Missed Opportunities, Innovation and Resource-Based Growth in Latin America" de William F. Maloney (The World Bank - December 2002) $)^{6}$, trabajo que se apoya en las investigaciones de numerosos historiadores, donde se subrayan los siguientes aspectos:

World Economic Forum (WeF), disponible en: http://reports.weforum.org/global-information-technology-report-2015/

6. William F. Maloney, "Missed opportunities, innovation and resource-based growth in Latin America", (The World Bank, disponible en: http://siteresources.worldbank.org/ DEC/Resources/Missed0Opportu1wth0in0Latin0America.pdf 
a) El lento crecimiento económico durante los siglos Xvin y xIX que distinguió a los países de América Latina se debió fundamentalmente a los patrones de asentamiento y los cultivos que llevaron a una desigual distribución del ingreso. Esta concentración preservó la influencia política de élites privilegiadas que condujeron a la marginación de gran parte de la población, medida por su difícil acceso al comercio, los recursos naturales, las instituciones financieras, la propiedad de los derechos, así como la enseñanza primaria.

b) Las preocupaciones sobre el control social, la extrema desigualdad de ingresos y débiles finanzas públicas, entre otras variables, condujeron a esfuerzos dramáticamente más débiles en América Latina hacia la educación universal que entre sus vecinos de Norteamérica.

c) Para el año 1870 más del 70\% de la población mayor de diez años en Australia, Estados Unidos, Canadá y Suecia estaba alfabetizada, lo que representa tres veces el porcentaje de Argentina, Chile, Costa Rica y Cuba, y cuatro veces el porcentaje de Brasil y México. América Latina progresó de manera desigual hacia estos niveles durante el próximo medio siglo. En 1925, Argentina, Uruguay, Chile y Costa Rica alcanzarían tasas de alfabetización de más del 60\%, mientras que México, Brasil, Venezuela, Perú, Colombia, Bolivia, Guatemala y Honduras alcanzarían el nivel del 30\% mucho más tarde.

d) Como una manifestación fundamental para el desarrollo de la innovación y una explicación parcial de las altas tasas de invención en Estados Unidos en los siglos XVIII y XIX, se argumenta que la preocupación respecto de las oportunidades para la obtención de beneficios de las invenciones contribuyó a la consolidación de un sistema de patentes que era probablemente, en el momento, el más favorable en el mundo para gente común. Esto en marcado contraste con México y Brasil, donde las patentes eran limitadas a los ricos o influyentes por los costos y procedimientos. También donde los derechos a organizar las corporaciones y las instituciones financieras se concedió con moderación, en gran parte para proteger el valor de los derechos que ya estaban en manos de poderosos intereses.

e) Además, la naturaleza de la educación en América Latina era menos técnica que en Escandinavia o las antiguas colonias inglesas. La educación universitaria en España era en gran parte religiosa y focalizada en el derecho, la filosofía y la teología, y algo de medicina. Este patrón se repitió en las colonias. La "Ilustración española" después de 1750 vio la creación de grupos de sociedades económicas que buscaban difundir las tecnologías del exterior y establecer bibliotecas en todo el país. España comenzó a entrenar a los ingenieros en la década de 1850, y por el año 1867 tenía solo una Escuela de Ingenieros Industriales, ubicada en Barcelona. América Latina en su mayor parte se quedó atrás de España y Portugal en el desarrollo de una clase técnica.

f) Un cuerpo de ingenieros capacitados a nivel local surgió a finales del siglo XIX en muchos países, pero esto puede haber sido demasiado poco y demasiado 
tarde. Como sugieren los datos recabados, Australia tenía por lo menos 5 veces el número de ingenieros de Chile o Colombia en 1920, y para 1926, Australia tenía 27 veces más graduados de escuelas técnicas per cápita que Argentina, quizás el país más educado en América Latina. Suecia tenía casi 10 veces la densidad de ingenieros que Colombia o Chile. Escandinavia para ese momento ya estaba exportando ingenieros. Además, no es clara la calidad de los recursos humanos que América Latina producía. A finales del siglo xIx, en Colombia y Chile, ingenieros locales se quejaban de que las empresas gubernamentales y privadas preferían importar ingenieros de Francia o de Estados Unidos para realizar tareas bastante sencillas.

g) En el caso de Australia, los historiadores hacen énfasis en el papel de la infraestructura no universitaria de la innovación para explicar la evolución dispar de la industria del trigo en Australia, Canadá y Argentina. En los tres países, el trigo tuvo un temprano y firme punto de apoyo, pero se convirtió en una gran industria en Canadá, en buena parte debido a la ayuda del gobierno para la agricultura en forma de estaciones experimentales, servicios de análisis de semillas y asistencia técnica. Una vez más, esta ayuda también se materializó en Canadá y Australia al lograr la alfabetización generalizada de la población rural, sin algo similar en América Latina. También hubo suministro de otros bienes públicos importantes menos relacionados con el conocimiento: por ejemplo, los graneros públicos y un sistema de clasificación de trigo que proporcionaba control de calidad, lo que dio a Canadá una ventaja sobre el trigo de Argentina, que tenía una reputación de calidad inferior y de falta de uniformidad. Además está la provisión de una extensa infraestructura institucional y científica, que fue reconocida como clave para el éxito de Canadá, en comparación con los esfuerzos poco efectivos del gobierno argentino.

h) Podría decirse que la capacidad técnica local inicialmente deficiente, exacerbada por el progreso tecnológico en otros lugares, llevó a la pérdida de liderazgo de Chile en materia de cobre en el transcurso de los dos últimos siglos. También ayuda a explicar por qué la empresa australiana BHP Billiton descubre y explota la mina La Escondida (la mayor del mundo) y pasa a ser la fuerza principal en la expansión de la producción de cobre de Chile en los años 1980 y 1990, a pesar de que la industria minera de Australia es mucho más joven que la de Chile.

La perspectiva histórica presentada en los párrafos precedentes resume el contexto y las razones por las que el tema educativo en América Latina no ha tenido la prioridad otorgada en otras latitudes. Por otro lado, el Programa Internacional de Evaluación de Estudiantes (PISA) del año 2012 nos ubica en la cola de la educación secundaria de los 65 países participantes, lo que es una prueba de que no estamos haciendo bien la tarea. ¿Pero está ocurriendo lo mismo en la educación de tercer nivel? 


\section{Cifras del pRESENTE}

Según el informe "Sistemas nacionales de ciencia, tecnología e innovación en América Latina y el Caribe", elaborado por la unesco (Oficina Regional de Ciencia para América Latina y el Caribe - 2010) ${ }^{7}$, es sorprendente y preocupante la proporción de profesionales graduados en ciencias sociales y humanidades, que para el año 2007 representa el 63\% del gran total (más de un millón), mientras ingeniería y tecnología representa el 17\%; y ciencias, un modesto $5 \%$.

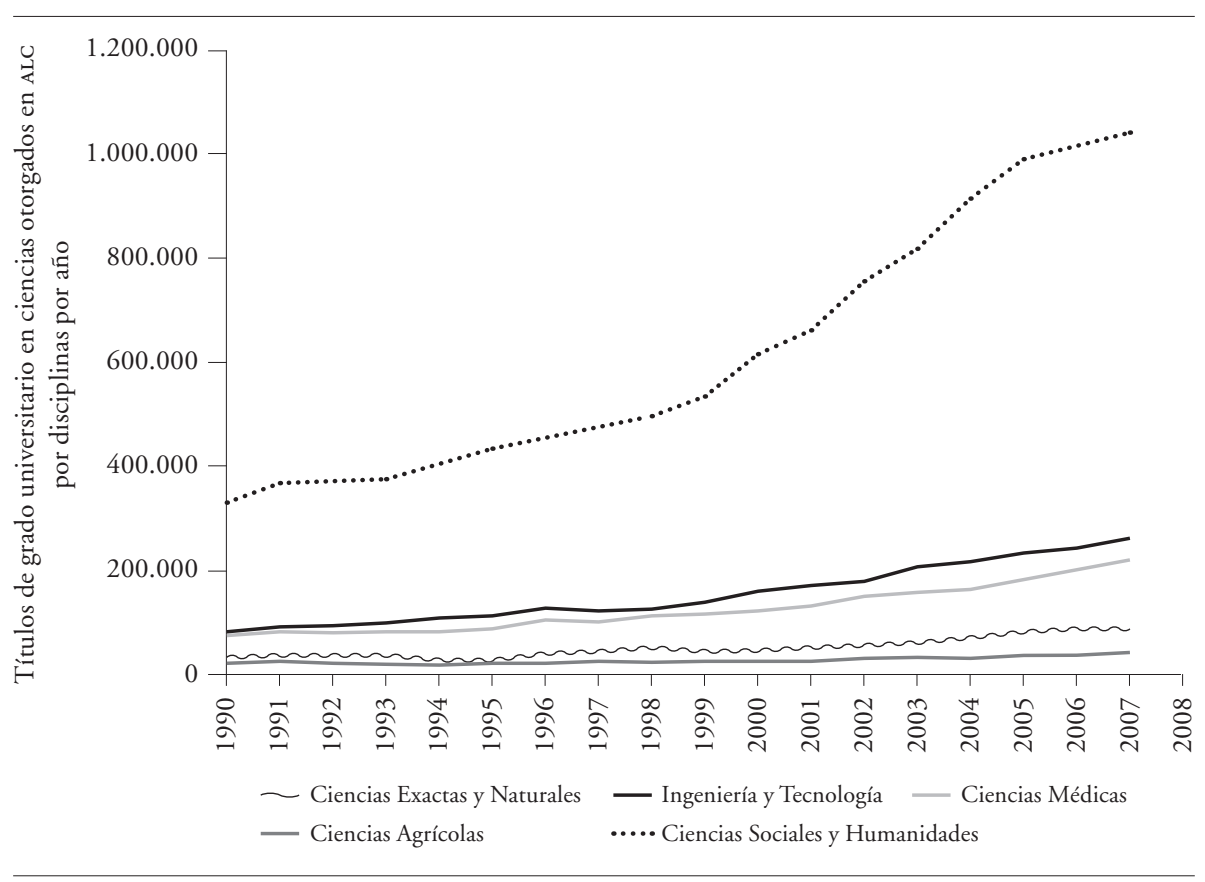

Sin negar la existencia de modalidades de innovación que no requieren I\&D ni laboratorios, ni que las ciencias sociales son fundamentales para el desarrollo de un país, la realidad indica que el grueso de la innovación exige el conocimiento y la aplicación de la ingeniería y las ciencias exactas. La educación de tercer nivel es costosa y supone dedicar importantes recursos para su funcionamiento y crecimiento, por lo tanto el perfil de los graduandos de América Latina, que se está obteniendo de esa cuantiosa inversión, no es compatible con las metas de una región que se sabe rezagada en un mundo donde la ciencia, la tecnología y la innovación, como trípode de la educación, son las prioridades de todos los países. 
Ampliemos la visión y veamos cómo estamos con relación a los países más desarrollados, los cuales en sus programas de gobierno y políticas de Estado le dan prioridad a los planes educativos, puesto que esta es la fuente de conocimientos y por lo tanto de creatividad e innovación, que debe verse materializada en un aumento de la productividad y competitividad.

Contar con personas que hayan alcanzado el nivel universitario es un primer paso fundamental (pero no suficiente) para fomentar la innovación. En el mundo global que caracteriza el siglo xxI, es necesario conocer qué están haciendo los otros países y cuán sólida es su fortaleza en materia de formación de recursos humanos de alto nivel.

Las estadísticas más recientes de que disponemos son del año $2008^{[8]}$. Se ha seleccionado un conjunto de países respecto de los cuales se muestran las cifras del total de graduados universitarios (tercer nivel), luego se desglosan los graduados en ciencias e ingeniería, y finalmente solo los de ingeniería.

\begin{tabular}{|l|r|r|r|r|c|}
\hline \multicolumn{5}{|c|}{ Año 2008} \\
\hline \multicolumn{1}{|c|}{ País } & Total graduados & $\begin{array}{c}\text { Ciencias e } \\
\text { ingeniería }\end{array}$ & Porcentaje \% & Ingeniería & Porcentaje \% \\
\hline China & 2.256 .783 & 1.143 .338 & $51 \%$ & 704.604 & $31 \%$ \\
\hline Francia & 287.234 & 100.257 & $35 \%$ & 41.023 & $14 \%$ \\
\hline Alemania & 322.651 & 118.486 & $37 \%$ & 40.129 & $12 \%$ \\
\hline Japón & 555.690 & 336.815 & $61 \%$ & 95.216 & $17 \%$ \\
\hline Corea del Sur & 315.204 & 129.641 & $41 \%$ & 77.238 & $25 \%$ \\
\hline EE.uv. & 1.580 .413 & 496.168 & $31 \%$ & 69.908 & $4 \%$ \\
\hline Reino Unido & 334.790 & 114.250 & $34 \%$ & 20.400 & $6 \%$ \\
\hline Argentina & 78.433 & 21.560 & $27 \%$ & 6.524 & $8 \%$ \\
\hline Brasil & 797.450 & 121.421 & $15 \%$ & 37.351 & $5 \%$ \\
\hline México & 336.810 & 116.835 & $35 \%$ & 52.826 & $16 \%$ \\
\hline Colombia & 107.683 & 29.657 & $28 \%$ & 25.767 & $24 \%$ \\
\hline
\end{tabular}

Fuentes: NSF - Science and engineering indicators / OECD.

El análisis de las cifras de la tabla permite explicar el explosivo desarrollo de Japón, Corea del Sur y China (en ese orden cronológico), al observar que en el año 2008 se graduaron 336.800 profesionales en las ramas de ciencias e ingeniería en

8. National Science Foundation - Science and Engineering Indicators, disponible en: http://www.nsf.gov/statistics/seind14/ 
Japón, 129.600 en Corea del Sur y 1.143 .000 en China, cifras que representan el $61 \%$, el $41 \%$ y el $51 \%$ del total de graduados de esos países, respectivamente. En el caso de Estados Unidos, tanto las cifras del cuadro anterior como sus modestos resultados en la evaluación de PISA provocaron una fuerte preocupación y reacción entre la clase dirigente, que los llevó a la publicación de dos densos informes elaborados por la National Academy of Sciences, la National Academy of Engineering y el Institute of Medicine: "Rising Above the Gathering Storm" (2005) y "Rising to the Challenge: U.S. Innovation Policy for Global Economy" (2012), donde se lleva a cabo un diagnóstico y se presentan un conjunto de recomendaciones para que ese país no pierda su condición de líder en materia de ciencia, tecnología e innovación.

Por otro lado, las cifras de los países de América Latina nos deberían hacer reflexionar, tanto las absolutas como los porcentajes'. Solo para mencionar los casos de dos países de la región:

\begin{tabular}{|c|c|c|c|}
\hline Pais & Población (millones) & $\begin{array}{l}\% \text { del PIB en } \\
\text { educación }\end{array}$ & $\begin{array}{l}N{ }^{\circ} \text { de graduados en } \\
\text { ciencias e ingeniería }\end{array}$ \\
\hline Corea del Sur & 49,1 & 4,9 & 129.641 \\
\hline Argentina & 43,4 & 5,1 & 21.560 \\
\hline Colombia & 46,7 & 4,9 & 29.657 \\
\hline
\end{tabular}

Fuente: CIA World Factbook y National Science Foundation - Science and engineering indicators.

Los tres países tienen una población similar, invierten casi el mismo porcentaje del pIB en educación, y sin embargo Corea forma 6 veces más profesionales en ciencias e ingeniería que Argentina y 4,4 veces más que Colombia. Estas cifras no contemplan el tema de la calidad, pero los resultados de la evaluación de PISA (aunque referidos a la educación secundaria) indican una alta probabilidad de que lo mismo ocurra con la educación universitaria.

\section{ESQUEMA DE LA RELACIÓN ENTRE EDUCACIÓN, INNOVACIÓN Y DESARROLLO}

La conclusión preliminar que podemos esbozar en este momento es que la tarea de fortalecer a la educación para que cumpla su función de pilar fundamental del desarrollo no la hemos cumplido. Para entender cabalmente dicha función es necesario que la clase dirigente de los países de América Latina tenga muy clara la

9. CIA World Factbook, disponioble en: https://www.cia.gov/library/publications/theworld-factbook/

National Science Foundation, Science and Engineering Indicators. 
estrecha relación de un conjunto de factores que deben operar en equilibrada armonía para alcanzar el desarrollo, todos teniendo como fuente primaria la educación.

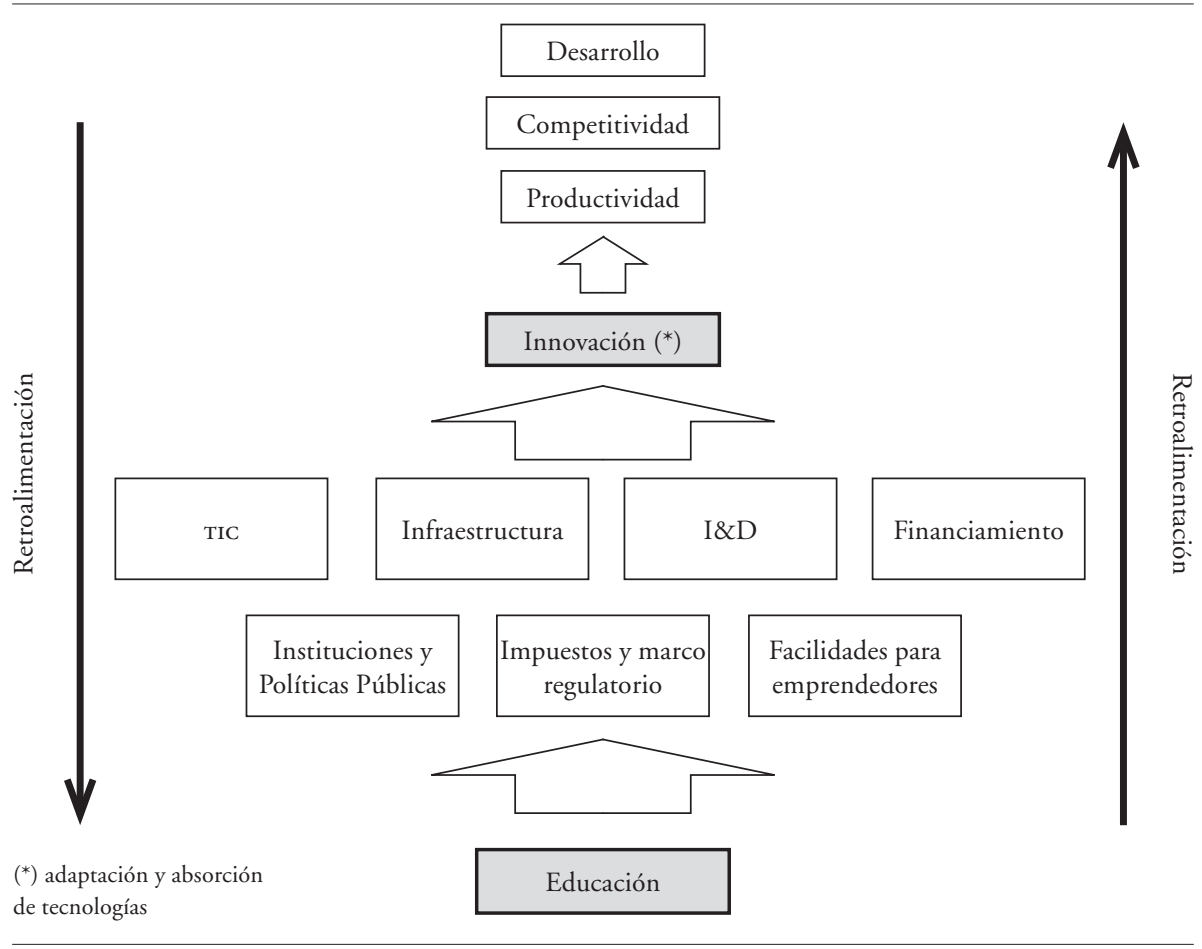

Fuente: elaboración propia.

Como bien se expresa en el esquema, la base de este edificio es la educación. En la medida que cada país cuente con los recursos humanos necesarios podrá ir construyendo y operando eficazmente las instituciones, sistemas, organizaciones y estructuras (para simplificar, los factores) que conforman el nivel que se destaca en el esquema. Por supuesto que esta es una tarea que se mide en décadas y que se logra con una alta dosis de perseverancia.

Por lo tanto es necesario subrayar varios objetivos y tareas que se deben considerar a la hora de introducir cambios, hacer reformas y diseñar la política de innovación, que propicie el surgimiento de un nuevo contexto que facilite la innovación:

a) La política de innovación debe aprovechar el conocimiento y la tecnología de otros países para su difusión en la economía local: los países de ingresos bajos y medianos deberían dar prioridad a la adaptación de los conocimientos mundiales a las necesidades locales.

b) Instituciones: los países en desarrollo deben dar apoyo directo a los proyectos innovadores mediante la provisión de las necesidades técnicas, financieras 
y de otro tipo; la eliminación de los obstáculos normativos o informales a los esfuerzos innovadores, como los procedimientos aduaneros o reglas relativas a la cooperación entre la universidad y la industria; la estimulación del cambio, como los programas para familiarizar a los escolares con la ciencia y la tecnología.

c) Marco legal: la mayoría de los países tienen la necesidad de reorientar sus estructuras establecidas para la investigación, la educación y similares.

d) Dado lo difícil que es introducir reformas a nivel nacional, las políticas del gobierno deben concentrarse en sectores específicos, teniendo en cuenta que siempre hay activos para explotar. Una acción bien articulada del gobierno con un paquete adecuado de medidas ayudará a asegurar el éxito y fomentar la confianza y la seguridad entre la sociedad.

e) Características culturales y de comportamiento - respetar las diferencias culturales y de comportamiento: al igual que los países desarrollados, los países en desarrollo tienen sus características específicas.

En la medida que los factores se van fortaleciendo es que se puede llevar a cabo una primera fase de innovación en la que se le debe dar prioridad a la adaptación y absorción de tecnologías sobre la investigación básica. La razón de esta afirmación es que la investigación básica y la innovación no son conceptos sinónimos; especialmente en países en desarrollo, donde la mayoría de las empresas operan muy por debajo de la frontera tecnológica, muy pocas empresas logran innovar. En otras palabras, las actividades de innovación e investigación básica están separadas. Los responsables de diseñar las políticas de ciencia, tecnología e innovación pueden perder una valiosa oportunidad para aumentar el empleo, los salarios y los niveles generales de vida, si se centran en la investigación básica en detrimento de tareas más modestas de modernización de la tecnología, tales como: diseño, ingeniería, capacidad de adquirir tecnología desarrollada fuera de la país y también la capacidad de gestión técnica y de organización para utilizar la tecnología más avanzada en las industrias básicas que operan por debajo de la frontera tecnológica.

En el tope del esquema de la relación entre educación, innovación y desarrollo destacan los conceptos de productividad, competitividad y desarrollo que representan los frutos de la instrumentación de un conjunto de políticas y decisiones como las descritas en los párrafos anteriores.

La nueva masa de conocimientos que genera un bien diseñado sistema educativo mejorará las habilidades y destrezas de los recursos humanos locales, que conjuntamente con las mencionadas políticas y decisiones permitirá iniciar la introducción de innovaciones en productos y procesos, como también lograr adaptaciones a las condiciones del mercado local. Sobre esta base se produce un natural aumento de la productividad, condición que luego conduce a un aumento de la competitividad, la cual permite abordar y ganar nuevos mercados, sobre to- 
do si se han alcanzado niveles de calidad para competir en el mercado global. En el diseño de la política de desarrollo, la clase dirigente debe determinar las áreas de fortaleza del país, con el propósito de afirmarlas y robustecerlas con carácter prioritario, dado que es en ellas donde las probabilidades de competir con éxito son mayores. En otras palabras debemos detectar los nichos de mercado donde somos competitivos.

En su publicación de julio de 2015, "El futuro de la productividad", la $\mathrm{OECD}^{10}$ subraya: "El crecimiento de la productividad es el principal impulsor de los niveles de vida”, y más adelante nos recuerda las palabras de Paul Krugman según las cuales la productividad consiste en "trabajar de forma más inteligente, no en trabajar más intensamente", es decir, refleja la capacidad de producir más mejorando la organización de los factores de producción gracias a nuevas ideas, innovaciones tecnológicas y nuevos modelos de negocio. Innovaciones tales como la máquina de vapor, la electricidad y la digitalización han propiciado cambios radicales en la producción de bienes y servicios, incrementando además los niveles de vida, el bienestar y el tiempo de ocio.

La innovación genera nuevas industrias, y por otro lado las empresas innovadoras crean buenos empleos. Los salarios de los trabajadores en empresas innovadoras y competitivas tienden a ser más altos. Por ejemplo, en las empresas que son competitivas y exportan (es decir que compiten con éxito a nivel internacional) se ha encontrado que pagan mejores salarios. Un reciente informe ${ }^{11}$ ("The Competitiveness and Innovative Capacity of the United States", Department of Commerce, January 2012) muestra que la mano de obra con formación en ciencia, tecnología, ingeniería y matemáticas (sTEM, por sus siglas en inglés) ganó un $26 \%$ más que sus contrapartes en ocupaciones no sTEM en Estados Unidos. Los trabajadores con perfil STEM también eran menos propensos al desempleo y el crecimiento de trabajos STEM en los últimos 10 años fue tres veces mayor que el crecimiento en empleos sin el perfil de sтем.

\section{La Difícil META DE UNA EdUCACión DE CALIdAd}

El cambio tecnológico es el motor del desarrollo. Sin embargo, también tiene un lado potencialmente oscuro. Nos referimos a que el cambio tecnológico crea ganadores y perdedores y a veces puede tener consecuencias adversas desde el punto de vista social, como es el desempleo. Esto ocurre cuando el cambio tecnológico es muy acelerado, generando nuevas tecnologías que aumentan la demanda de

10. "El futuro de la productividad", oeCD, disponible en: http://www.oecd.org/eco/Elfuturo-de-la-productividad.pdf

11. "The Competitiveness and Innovative Capacity of the United States", Department of Commerce, January 2012, disponible en:

http://www.esa.doc.gov/reports/competitiveness-and-innovative-capacity-united-states 
trabajadores calificados, que el sistema educativo no es capaz de formar. De esta manera los ingresos de algunos aumentarán mucho más que los de otros. Si los trabajadores tienen habilidades flexibles y si la infraestructura educativa se expande y actualiza lo suficiente, entonces la oferta de personal calificado aumentará a medida que aumenta la demanda. Pero en la realidad eso no está sucediendo, de acuerdo a las encuestas señaladas, los empresarios están insatisfechos con el perfil de los recién graduados.

La complejidad del tema se profundiza cuando consideramos los estudios promovidos por el Center for Global Development, en especial "Schooling Is Not Education!"12, donde destacan colaboradores como Lant Pritchett y Nancy Birdsall. En dichos estudios se han venido acumulando pruebas de que el aprendizaje se ha estancado en los sistemas escolares de países en desarrollo, como se ha demostrado por los bajos niveles de aprendizaje, así como por los pequeños incrementos en el aprendizaje a través de los grados. Son numerosas y sólidas las evidencias de que muchos estudiantes están aprendiendo muy poco en sus escuelas. En otras palabras, nos hemos comprometido a cumplir metas de aumentar el número de alumnos inscritos en las escuelas, donde están presentes pero no aprenden. Dentro de dicho estudio destacan los siguientes aspectos:

a) A nivel mundial, la educación es un sector económico importante. El gasto público en educación representa el 5,4\% del PIB en Brasil y Reino Unido; el 5,5\% en Ghana y Estados Unidos. En Kenia y Uganda, la educación representa alrededor del 15\% del gasto público. Sin embargo, estos altos porcentajes dedicados a la educación no necesariamente conducen a una mejora de los resultados económicos. Como una muestra de la diferente eficiencia en la utilización de los recursos se presenta el caso de Kenia para el año 2010, donde los habitantes mayores de 15 años tenían un promedio de escolaridad superior al promedio francés en 1985. Sin embargo, para el año 2010 el PIв per cápita de Kenia fue solo el 7\% del PIB per cápita de Francia para 1985. Kenia representa una tendencia entre los países en desarrollo: aumentó masivamente la matrícula, pero los ingresos se han estancado en las últimas décadas. En términos más generales, el vínculo o relación que se pueda establecer entre la educación y el crecimiento económico es muy frágil.

b) En India, una encuesta a nivel nacional revela la evidencia de que solo alrededor de un tercio de los niños de $5 .^{\circ}$ grado puede realizar una división larga, y una tercera parte no puede realizar la resta de dos dígitos. Casi la mitad de los estudiantes de $5 .^{\circ}$ grado no puede leer un texto de $2 .^{\circ}$ grado y uno de cada cinco no puede seguir un texto de $1 .{ }^{\text {er }}$ grado. El $60 \%$ de los niños matriculados en $8 .^{\circ}$ grado no saben utilizar una regla para medir un lápiz. Solo el $27 \%$ de los niños 
de India que terminan la escuela primaria puede leer un pasaje sencillo, realizar una división, leer el reloj y manejar dinero, aunque los estudiantes deberían dominar cada una de estas habilidades al final del $2 .^{\circ}$ grado de la escuela. Estas estadísticas contrastan fuertemente con la tasa de alfabetización oficial del $81 \%$ de jóvenes reportada por la UnESCO.

c) Pruebas internacionales de matemáticas como las "Trends in International Mathematics and Science Study" (TIMss) ${ }^{13}$ sugieren que el estudiante medio de $8 .^{\circ}$ grado en Ghana tiene una calificación en dicha prueba que lo coloca en la parte inferior del 0,2\% de los estudiantes de Estados Unidos. Incluso en los países considerablemente más ricos, como Chile, la brecha de aprendizaje es aún grande: el estudiante chileno promedio estaría en la parte inferior del 6,4\% de los estudiantes de Estados Unidos, con base en los resultados del Timss.

d) La siguiente tabla presenta los puntajes timss promedio para una serie de países en desarrollo, como un percentil del rendimiento de estudiantes daneses.

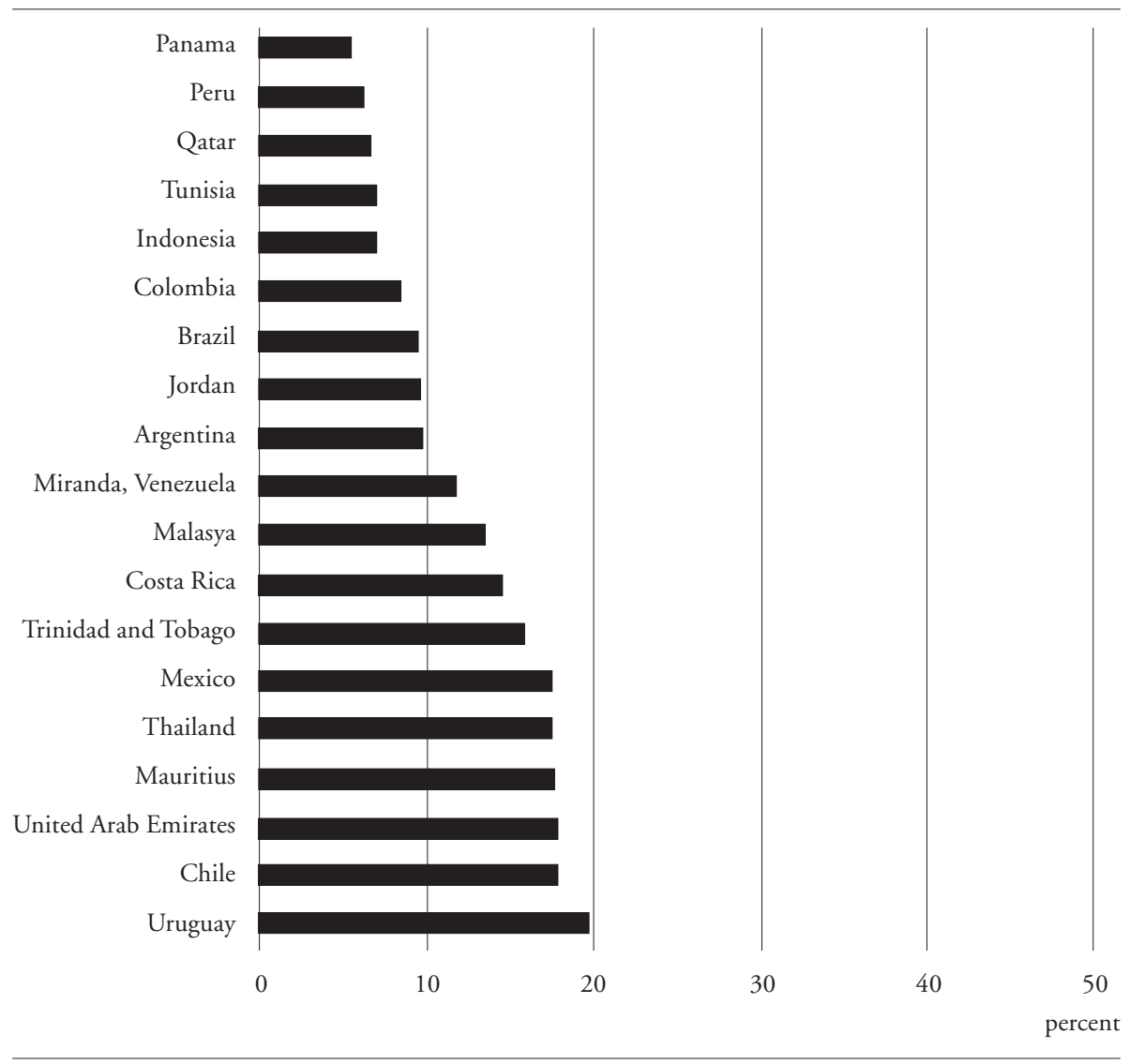

13. http://timssandpirls.bc.edu/ 
La lectura de esta tabla nos indica que los estudiantes de Panamá, Perú, Colombia, Brasil y Argentina obtuvieron resultados en las pruebas timss que corresponden a un rango del $5 \%$ al 10\% de los resultados obtenidos por los estudiantes de Dinamarca. También que los estudiantes de Venezuela, Costa Rica, México, Chile y Uruguay obtuvieron resultados en las pruebas Timss que corresponden a un rango del $10 \%$ al $20 \%$ de los resultados obtenidos por los estudiantes de Dinamarca.

e) La comparación de resultados para los grupos desfavorecidos en el interior de los países en desarrollo es aún peor; en el caso de Chile, la brecha entre los resultados de estudiantes más ricos y los más pobres que participaron en el Programa de Evaluación Internacional de Alumnos (PISA) es superior a 100 puntos, sobre una escala de 100 a 600 .

\section{Políticas exitosas de Ciencia, Tecnología e Innovación (cti)}

Además de los países líderes en ciencia, tecnología e innovación, como es el caso de Estados Unidos, Japón y Alemania, hay un conjunto de países que en las últimas décadas han llevado a cabo reformas de diferente naturaleza, preparándose para ser clasificadas como sociedades basadas en el conocimiento.

Dichas reformas con resultados positivos les han permitido acercarse a los países líderes, entrando a competir en muchos campos, explorando las fronteras del conocimiento. Los casos que se analizan son los de Corea del Sur, Irlanda y Finlandia, de los cuales vamos a extraer conclusiones aplicables a cualquier país o región. Son países de economías medianas, de escasos recursos naturales, de población y superficies pequeñas pero con un alto y sostenido crecimiento del PIB y el PIB per cápita en las últimas décadas.

El denominador común de estos países es haber contado con la decisión y el soporte político al más alto nivel, para diseñar una política de сті que tuviera sus efectos sobre toda la estructura del Estado. Como los recursos naturales eran muy escasos, asumieron que deberían fortalecer lo único que los podría diferenciar: los recursos humanos. Con las naturales diferencias de cultura y estilos, en los tres países se hizo hincapié en alcanzar el máximo de matrícula para la educación primaria y secundaria, de tal manera que toda la población tuviera una formación básica de primera calidad, meta que fue alcanzada hace varios años, según se evidencia de los resultados de PISA, donde los estudiantes de los tres países alcanzaron en la prueba de 2012 una calificación superior al promedio de los 65 países que participan en el Programa.

Paralelamente al esfuerzo central de fortalecer la educación básica, se llevaron a cabo otras iniciativas en el campo de la educación, como la actualización de los programas universitarios, la dotación de sus laboratorios, un acercamiento de las universidades con las empresas y un programa de becas para estudios de posgrado en el exterior, entre otras. 
Con el propósito de coordinar los programas, proyectos, asignación de recursos y afinar las estrategias se crearon instituciones (o se modificaron las existentes) como las responsables de la implementación de las políticas de CTI, con representación en los gabinetes ejecutivos y con la misión de exigir la prioridad que sus programas merecen. Estas nuevas instituciones pueden ser dos o tres, para atacar los diferentes frentes de trabajo (programas de I\&D, definición de las áreas prioritarias donde el país tiene mayor potencial, financiamiento a los innovadores, vinculación industria-universidad-innovadores, relación con otros organismos oficiales, participación en el diseño y actualización de los programas educativos a todos los niveles, fomento de las actividades de los emprendedores e innovadores, entre otras) que se derivan de la división del trabajo, que se establece en un proyecto tan complejo y de largo plazo como es el que nos ocupa. Cada una de dichas instituciones con el compromiso de cumplir con sus objetivos y la permanente revisión de estos debido a la cambiante naturaleza de la innovación.

La gran tarea del Estado -sin la cual no funcionaría ninguna política de CTIes fortalecer y optimizar la infraestructura, sobre todo la relacionada con las comunicaciones e internet. Esto como condición fundamental para atraer capital extranjero, que acudirá si observa una infraestructura eficiente, recursos humanos preparados (o al menos instituciones donde se estén formando), esquemas de financiamiento para los nuevos empresarios y variables macroeconómicas estables, que estén en sintonía con la economía global del siglo xxi.

En el caso de los tres países mencionados esto fue un proceso que llevó años, pues eran países que en la década de 1960 tenían todas las características del subdesarrollo y marcados por la pobreza. A su debido tiempo todos fueron tomando decisiones que contaron con soporte político al más alto nivel, tanto para diseñar una política de CTI como para mejorar la educación y la infraestructura y para ir buscando los recursos financieros para llevar a cabo los proyectos y programas que les aliviaron la transición hacia la sociedad del conocimiento ${ }^{14-15}$.

Esta es una tarea conjunta del sector público y el sector privado, ambos son indispensables. Al Estado le corresponde tomar la iniciativa e ir levantando las principales columnas en ciencia, tecnología e innovación. Luego el sector privado irá ocupando su lugar, elaborando los tejidos industriales, empresariales, de nuevos emprendedores e innovadores y también de inversionistas locales y extranjeros, atraídos por un ambiente donde se construye el futuro.

14. A Policy Innovation, World Bank.

15. Innovation Policy, A Guide for Developing Countries, World Bank Institute 2010, disponible en: https://openknowledge.worldbank.org/bitstream/handle/10986/2460/54893 0PUB0EPI11C10Dislosed061312010.pdf 


\section{LA INNOVACIÓN, CAMBIOS QUE INTRODUCE EN LA ESTRUCTURA DEL MERCADO DE TRABAJO Y PERSPECTIVAS DESDE EL INICIO DEL SIGLO XXI}

La revolución tecnológica que estamos viviendo desde finales del siglo pasado, ha venido cambiando gradualmente el mercado de trabajo, exigiendo nuevas habilidades, destrezas y conocimientos a los jóvenes que se están incorporando a dicho mercado.

Para tener una visión más completa, primero debemos conocer cómo han evolucionado los sectores básicos de la economía, que son los que demandan esos nuevos conocimientos. En un largo período de más de 60 años, de 1948 a 2011, en Estados Unidos se puede observar el vigoroso crecimiento del sector servicios, que para el año 2015 debe haber superado el nivel del $70 \%$, mientras la manufactura pasó del $30 \%$ a menos del $10 \%$. Es respecto de este contexto que debemos analizar los cambios ocurridos en el mercado de trabajo.

us employment by sector, \% of total employment

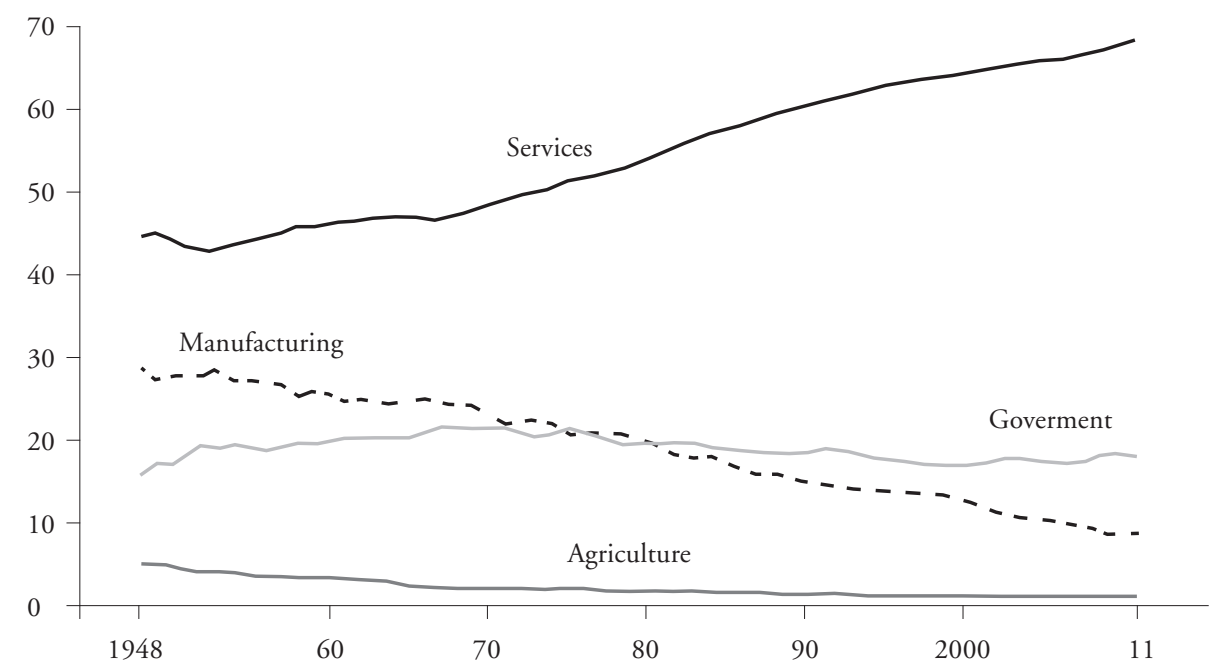

Source: us Boreau of Labour Statistic.

En el informe "OECD Skills Outlook 2013"16 se incluye un gráfico similar al anterior pero referido a la Unión Europea, ratificando que la evolución de los sectores muestra una fuerte tendencia de la polarización, en función de la naturaleza de las habilidades del trabajador. 
Change in the share of employment, by industrial sectors

Percentage change in share of of employment relative to 1980 , OECD average

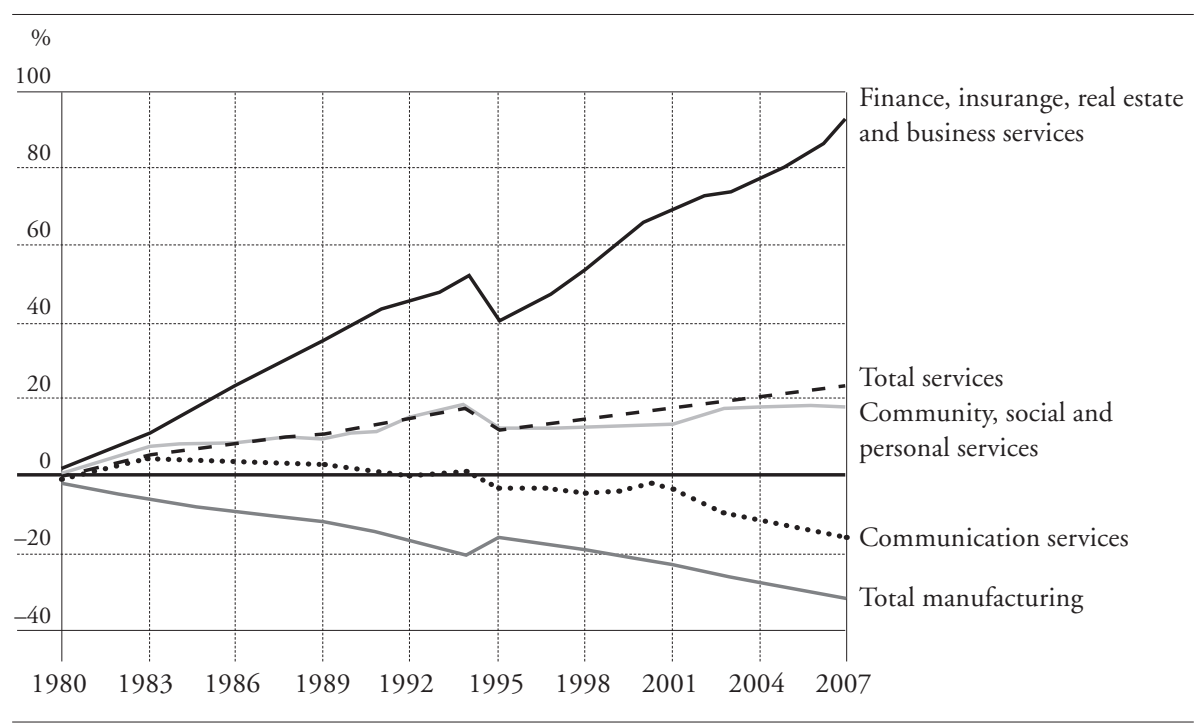

Se definen tres niveles de ocupaciones:

- Trabajadores de alta educación (high educated workers), grupo que incrementa hasta en un $20 \%$ la demanda.

- Trabajadores de mediana educación (medium educated workers), grupo que ve disminuida la demanda en un $8 \%$.

- Trabajadores de baja educación (low educated workers), grupo que ve disminuida la demanda en un $12 \%$.

Algo similar se puede observar en la evolución de los sectores básicos de la economía en Colombia ${ }^{17}$. En el período de cuarenta años que se muestra a continuación el sector servicios (servicios más comercio), que representaba el 52,20\% del piв para la década 1970-1979, subió al 59,30\% en la década 2000-2009, es decir, ganó un 7,1\% del pIB. En la dirección opuesta se encuentra la agricultura, sector que redujo en un 4,50\% su participación en el PIB en el mismo período. 


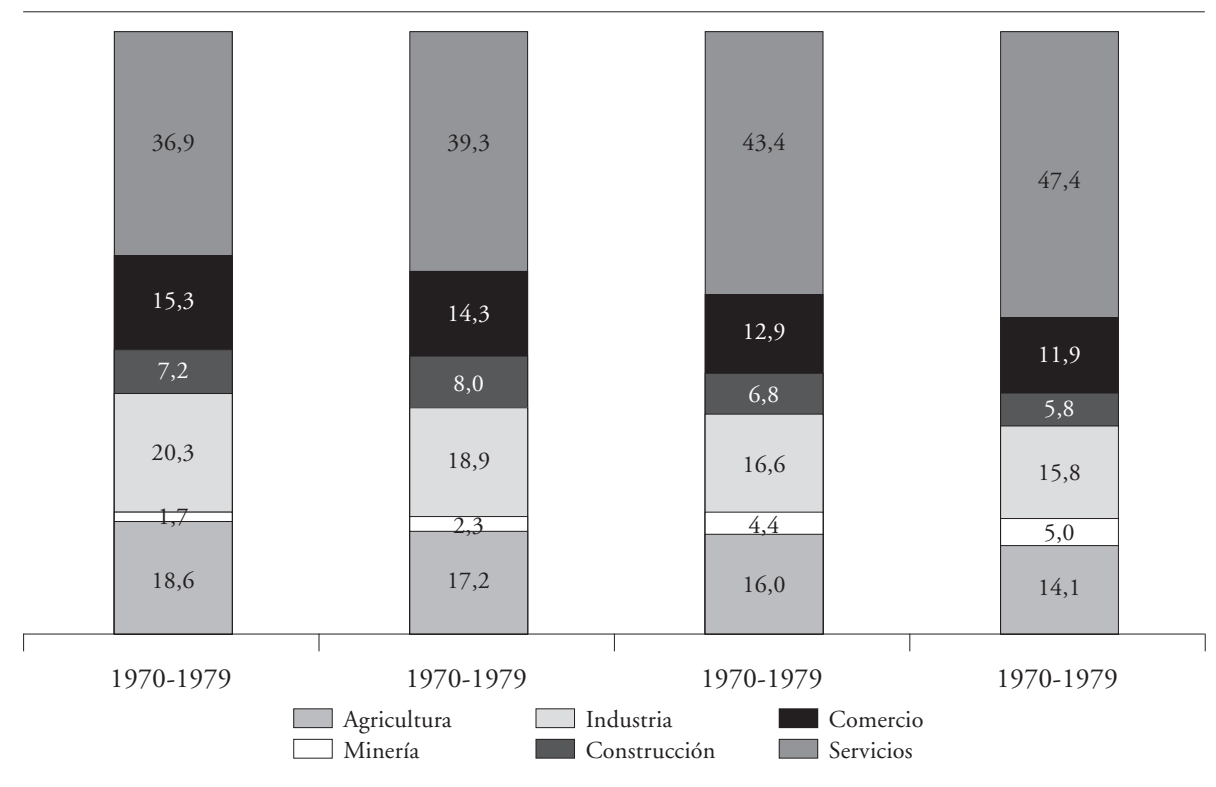

Una de las características de cómo ha cambiado la demanda de mano de obra en función de su nivel de preparación es la polarización del mercado de trabajo que se viene dando desde finales del siglo pasado. Para presentar evidencias de esta afirmación nos basamos en estadísticas recientes de Estados Unidos, más específicamente de "Economic Letter" (Federal Reserve Bank of Dallas, May 2014) de donde proceden los siguientes gráficos:

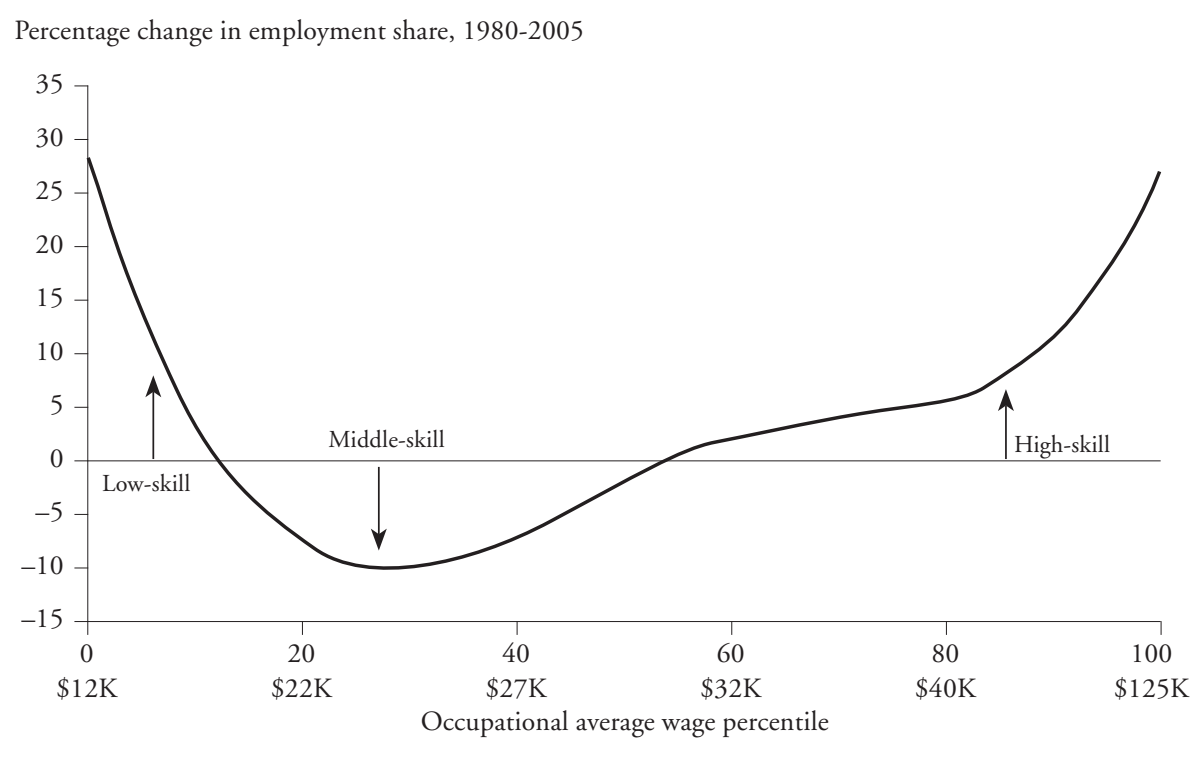




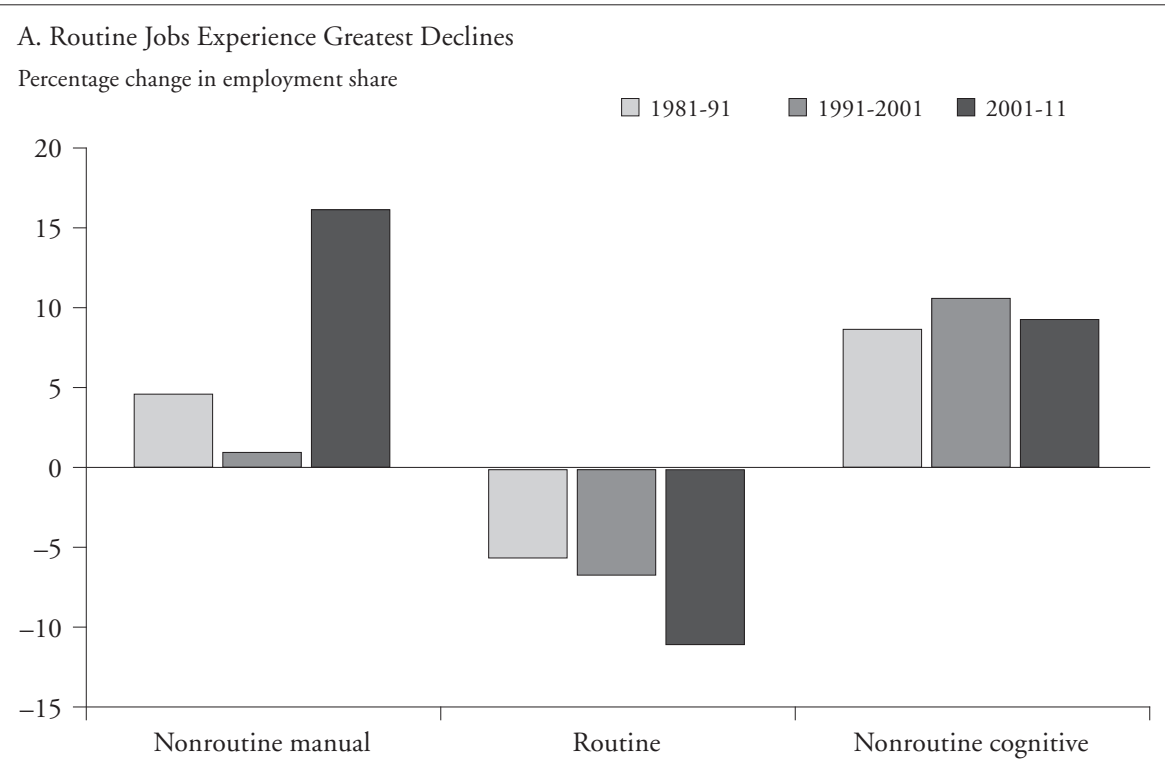

La lectura de los gráficos anteriores ${ }^{18}$ expresa claramente que los más afectados son los empleos medios de personal calificado en Estados Unidos, acelerando la polarización del mercado de trabajo. La distribución de los puestos de trabajo por nivel de habilidad ha cambiado dramáticamente desde 1980. El número de puestos de trabajo que requieren niveles medios de habilidad se ha reducido (en el gráfico anterior en los oficios clasificados routine, se observa que con cada década la tasa negativa va creciendo), mientras que el número en ambos extremos de la distribución, es decir, aquellos que requieren de altos y bajos niveles de habilidad, mantiene una tasa de crecimiento positiva.

Esta disminución en los empleos medios no es impulsada por los cambios en las instituciones del mercado de trabajo, como la disminución de la presencia de sindicatos, se debe al aumento en la automatización de las tareas rutinarias, una relativa escasez de trabajadores calificados y, en menor medida, a la reubicación de puestos de trabajo fuera del país. El número de personas que realizan tareas de baja calificación, bajos salarios y tareas manuales ha crecido, al igual que los puestos de trabajo de alta calificación y remuneración, con tareas no rutinarias que implican la resolución de problemas.

Si pensamos que la polarización del mercado de trabajo es una particularidad de Estados Unidos, David Autor, del miт Department of Economics, responde a este interrogante en su artículo "The Polarization of Job Opportunities in the

18. "Economic Letter", Federal Reserve Bank of Dallas, May 2014, disponible en: http:// www.dallasfed.org/research/eclett/ 
U.S. Labor Market Implications for Employment and Earnings” (April 2010), donde deja claro que también en la Unión Europea ocurre lo mismo: "Los números revelan una concordancia notable en la evolución del empleo en Estados Unidos y la Unión Europea: las ocupaciones de alto nivel de educación (directivos, profesionales y técnicos) están aumentando; ocupaciones de educación media (oficinistas, artesanía y oficios, operadores y montadores) están en declive; y ocupaciones de servicio con un nivel bajo de educación también están creciendo"19.

Otro aspecto de suma importancia es la percepción que tienen las empresas y las universidades sobre el grado de preparación de los recién graduados. En el informe de la consultora McKinsey \& Company, "Education to Employment: Getting Europe's Youth into Work"20, se muestran las divergentes opiniones de los actores del proceso:

\section{Respondents who agree that graduates/new hires are adequately prepared, $\%$}

35

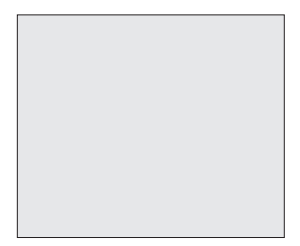

employers $^{1}$

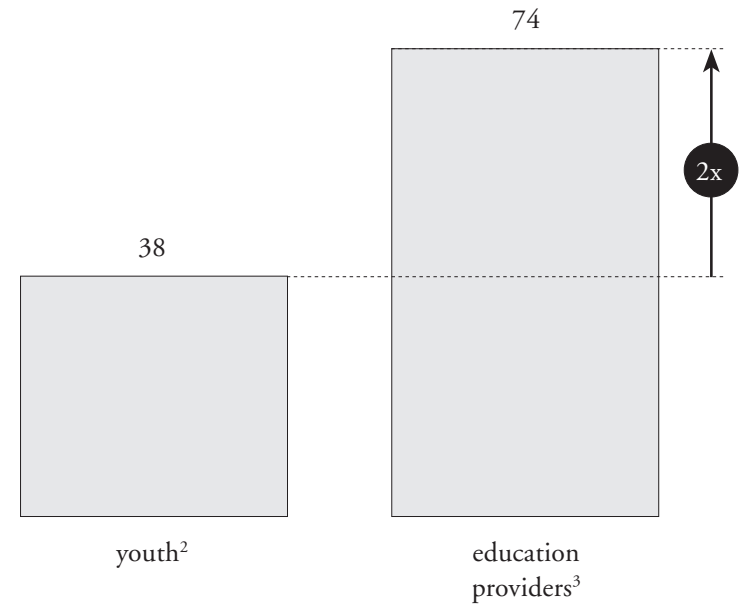

19. DAvid Autor, "The polarization of job opportunities in the U.S. labor market implications for employment and earnings", April 2010, disponible en: http://economics. mit.edu/files/5554

20. "Education to employment: Getting Europe's youth into work", McKinsey \& Company, disponible en: http://www.mckinsey.com/insights/social_sector/converting_education_to_employment_in_europe 
Employers who believe lack of skills cause significant problems or are detrimental to business, ${ }^{1} \%$

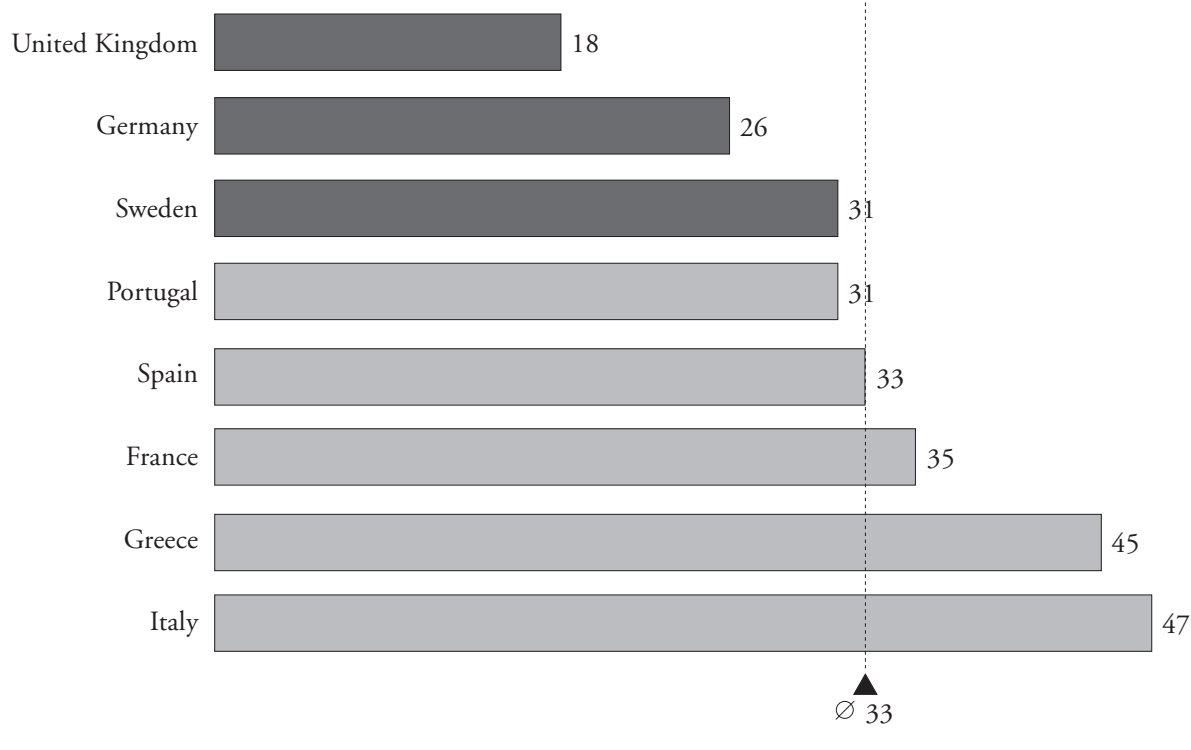

Sin negar que todo joven que se incorpora a una empresa deba pasar por un período de entrenamiento, lo que nos muestra el estudio es que los empresarios manifiestan un alto grado de insatisfacción con las habilidades del personal que recién se incorpora a sus filas. Llaman la atención las diferentes respuestas que se obtienen de la pregunta: "Encuestados que están de acuerdo con que los recién graduados están adecuadamente preparados" (Respondents who agree that graduates are adequately prepared), donde las empresas y los propios jóvenes no tienen una buena percepción de su preparación (35\% y 38\%), mientras que los proveedores de la educación (universidades o escuelas técnicas) consideran en un 74\% que sí están bien preparados y que por lo tanto ellos como instituciones están haciendo un buen trabajo.

La falta de una preparación adecuada tiene un alto costo que es el desempleo. Para tener una idea de la magnitud del problema acudimos nuevamente al estudio de McKinsey, donde se incluye el siguiente gráfico, que contempla los niveles de desempleo entre jóvenes de 15 a 25 años de edad, de 8 países de Europa más el promedio de la Unión Europea. Destacan Grecia, España, Portugal e Italia (en ese orden) con tasas de desempleo que superan el 35\% en el año 2013. El promedio de la Unión Europea alcanza el 23\%, nivel donde también se ubican Francia y el Reino Unido. 
Youth unemployment has risen across the EU since 2008

Unemployment rates, youth, $1 \%$

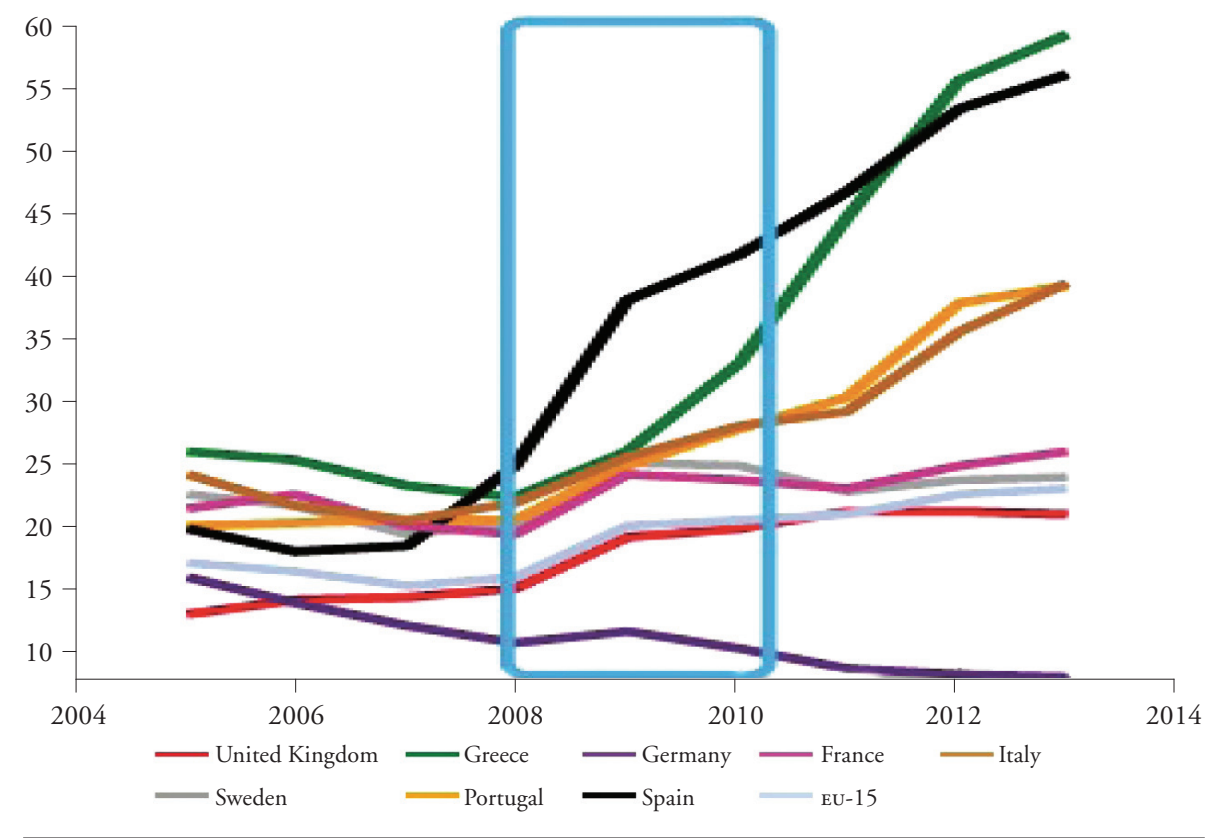

Un aspecto poco conocido sobre el desempleo que analiza el mencionado estudio de McKinsey es el costo para la sociedad de aquellos jóvenes que no estudian, ni trabajan, ni están siendo entrenados (grupo designado con la sigla NETE), que en España subió un $27 \%$ desde 2008 hasta 2009 y ha estado subiendo constantemente desde entonces.

El costo para la Unión Europea de la juventud NETE es enorme: según una estimación del costo anual de dicha población, tanto en términos de costos directos como de la producción no realizada, fue de $€ 153.000$ millones en 2011. No menos importante es el precio de la falta de trabajo a nivel individual. Los estudios de la generación que alcanzó la mayoría de edad en la década de 1980 han encontrado que los que soportan un período de desempleo antes de los 23 años sufren consecuencias a largo plazo, ganando del 12\% al 15\% menos que sus pares cuando llegan a los 42 años de edad. Trabajar en empleos provisionales o de media jornada a una edad temprana tiene un impacto similar.

Para darle contexto al análisis de toda esta problemática, veamos en el siguiente gráfico ${ }^{21}$ cómo se comportan otras variables: 


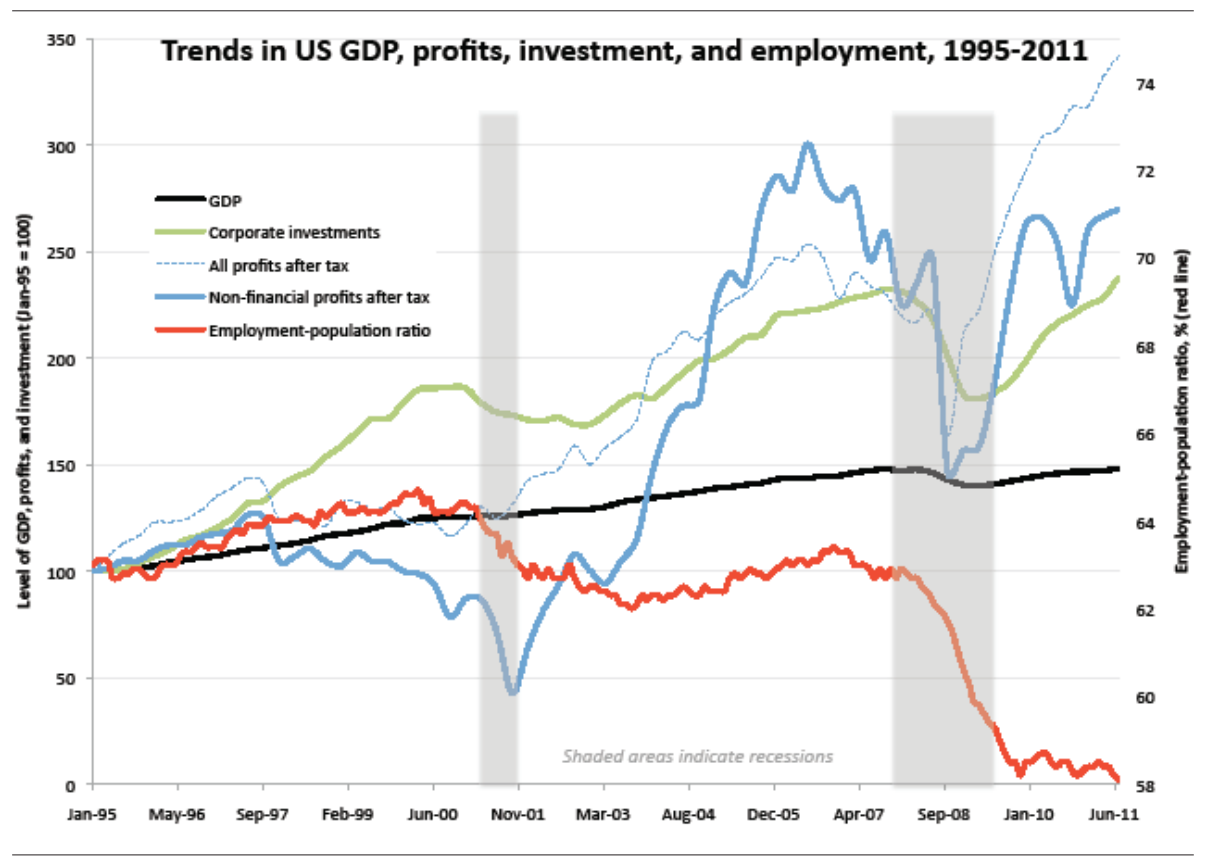

Fuente: Andrew McAfee Blog.

El período abarca un lapso de 16 años (1995-2011) donde se observa la evolución de las principales variables macroeconómicas de Estados Unidos. Las variables son el PIB (GDP en inglés) con la línea negra, inversión corporativa, beneficios después de impuesto, beneficios de las empresas no financieras y porcentaje de empleados sobre la población total. Todas las variables (con sus altibajos) presentan una tendencia creciente menos la línea roja del porcentaje de empleados, sobre todo después de la recesión de los años 2007-2008, donde presenta una profunda caída, de la cual no se ha recuperado. Es interesante observar que desde 1995 hasta 2007 se mantuvo alrededor del 63\%, y para 2011 había bajado al 58\%. Al cruzar esta información con los crecimientos del PIB, la inversión y los beneficios corporativos, se puede deducir que aumentó la productividad al haber disminuido el número de trabajadores, cuyos trabajos fueron automatizados, como lo indica el fuerte aumento de la inversión corporativa. Esto es lo que ha venido ocurriendo en los países más industrializados, pero en el caso de los países emergentes como América Latina el proceso es un poco diferente, los bajos niveles de innovación conducen a una baja productividad, lo cual nos hace menos competitivos y generamos pocos empleos. Cuando el capital extranjero llega a nuestros países, por lo general trae tecnologías de avanzada y de escasa capacidad para generar nuevos puestos de trabajo.

Para ilustrar el punto de la baja productividad de América Latina nos apoyamos en el informe de la CEPAL "Cambio estructural para la igualdad, Una visión 
integrada del desarrollo" (2012) 22 , donde se incluye el indicador "productividad relativa", término que se define como la productividad del trabajo relativa a la de Estados Unidos, promedio entre 2001 y 2010 (promedio simple). En este indicador, América del Sur incluye a Argentina, Brasil, Chile, Colombia, Ecuador, Paraguay, Perú, Venezuela y Centroamérica (Costa Rica, Honduras y Panamá).

\begin{tabular}{|l|c|}
\hline \multicolumn{1}{|c|}{ País } & Productividad relativa (\%) \\
\hline Argentina & 25,7 \\
\hline Brasil & 11,7 \\
\hline México & 19,8 \\
\hline Asia en desarrollo (a) & 33,8 \\
\hline América del Sur & 12,1 \\
\hline Centroamérica & 11,0 \\
\hline Economías maduras (intensivas en recursos naturales) (b) & 71,3 \\
\hline Economías maduras & 76,3 \\
\hline
\end{tabular}

(a) Filipinas, Hong-Kong, Indonesia, Malasia, República de Corea, Singapur y Tailandia.

(b) Australia, Dinamarca, Finlandia, Irlanda, Noruega y Nueva Zelanda.

El significado de las cifras del cuadro anterior es que el trabajador promedio de América del Sur, con una productividad relativa del $12 \%$, produce 8 veces menos que su similar de Estados Unidos y casi 3 veces menos que sus colegas de Asia.

En este momento es oportuno señalar que cuando presentamos el "Esquema de la relación entre educación, innovación y desarrollo", en su cúspide se ubica el desarrollo, como producto final y meta de un largo proceso que tiene como requisitos indispensables la productividad y la competitividad. Con esta baja productividad sobre nuestras espaldas es doloroso concluir que el desarrollo de América Latina es una meta lejana.

\section{Susceptibilidad De los EMPleos De SER COMPUTARIZAdos}

En un interesante ensayo ${ }^{23}$, "The future of employment: how susceptible are jobs to computerisation?”, de septiembre de 2013, los investigadores Carl Benedikt

22. CEPAL, "Cambio estructural para la igualdad, Una visión integrada del desarrollo, 2012, disponible en: http://www.cepal.org/pses34/noticias/documentosdetrabajo/4/47424/2012ses-34-cambio_estructural.pdf

23. Carl Benedikt Frey y Michael A. Osborne, "The future of employment: How susceptible are jobs to computerisation?”, 2013, disponible en: http://www.oxfordmartin. ox.ac.uk/downloads/academic/The_Future_of_Employment.pdf 
Frey y Michael A. Osborne, de la Universidad de Oxford, intentan responder cuán susceptibles son los empleos de ser computarizados, y para esto aplican una metodología que determina la probabilidad que tienen 702 oficios de ser automatizados, lo que significaría la pérdida de ese puesto de trabajo.

Esta situación resume un viejo temor ya expresado en 1930 por el economista inglés John Maynard Keynes cuando escribió un ensayo donde manifestaba su preocupación por una nueva enfermedad que llamaba el "desempleo tecnológico", que se generaba debido a los descubrimientos de medios para economizar mano de obra, que superaban el ritmo al que es posible encontrar nuevos usos para esa mano de obra.

Frey y Osborne tomaron en cuenta diferentes aspectos:

a) Los últimos avances en los campos de machine learning (ML, rama de la inteligencia artificial cuyo objetivo es desarrollar técnicas que permitan a las computadoras aprender) y mobile robotics (MR, robots capaces de movimiento en un ambiente, que pueden ser dirigidos por una persona o tener autonomía).

b) La tendencia al abaratamiento de los costos de todos los componentes de la computación y de la comunicación.

c) La propensión a substituir los puestos de trabajo de rutina en la manufactura, por oficios no rutinarios; tal es el caso de los automotores sin chofer de Google, que para el año 2012 ya habían superado complejas pruebas de tránsito. Esta función de manejar un automóvil era considerada en el año 2004, por prestigiosos investigadores, como no susceptible de automatización, dadas las miles de variables que concurren en el manejo y que la percepción humana logra armonizar sin mayor problema.

d) Las nuevas técnicas de minería de datos (un campo de las ciencias de la computación que intenta descubrir patrones en grandes volúmenes de conjuntos de datos, utiliza los métodos de la inteligencia artificial, estadística y sistemas de bases de datos, y su objetivo general consiste en extraer información de un conjunto de datos y transformarla en una estructura comprensible para su uso posterior), la cual ha mejorado la calidad de la investigación jurídica y también el acceso constante a la información sobre las fluctuaciones del mercado, enriqueciendo la eficacia de la toma de decisiones gerenciales.

e) La disponibilidad de la big data, con lo que una amplia gama de tareas cognitivas no rutinarias se están convirtiendo en "computarizables" (palabra no está registrada en el Diccionario de la Real Academia). Los ordenadores pueden procesar mejor los cálculos necesarios cuando nos enfrentamos con grandes conjuntos de datos. Los algoritmos ML que se ejecutan en ordenadores son, en muchos casos, más capaces de detectar patrones que los humanos.

f) Los grandes avances de la robotización y la reducción de precio de los robots. Un ejemplo es Baxter, un robot de propósito general que para aprender una 
tarea no necesita de una programación previa. Solo es necesario que la primera vez un trabajador lo guíe por las diferentes etapas de la tarea que debe ejecutar y Baxter las incorpora a sus rutinas.

La conclusión del ensayo "The future of employment: How susceptible are jobs to computerisation?” es que el $47 \%$ del empleo total de Estados Unidos está en alto riesgo, lo que significa que dichas ocupaciones son potencialmente automatizables en un número indeterminado de años, tal vez una o dos décadas. Los autores señalan que se focalizaron en los avances tecnológicos a corto plazo en ML y Mr. Evitan hacer predicciones sobre el tiempo que puede tomar superar diversos cuellos de botella de ingeniería para llegar a la automatización de un oficio.

\section{EDUCACIÓN-INNOVACIÓN Y DESIGUALDAD SOCIAL}

Sería una grave omisión tratar el tema de la relación educación-innovación sin abordar la grave situación de abandono de la juventud en América Latina y el Caribe (ALC), la cual conforma una buena parte de la población informal y desempleada. En ocasión del Día Internacional de la Juventud en el año 2015, la OIT destacó que es urgente adoptar estrategias integradas para hacer frente a esta situación que tiene el potencial de generar desaliento y frustración entre quienes recién entran al mercado laboral.

La crisis del empleo juvenil en ALC afecta a casi ocho millones de jóvenes que están desempleados y a otros 27 millones que están ocupados pero en condiciones de informalidad, generalmente con bajos ingresos, inestabilidad laboral, sin protección social ni derechos. Estas cifras forman parte de un mal mayor, ya que según FORLAC (Programa de la oit para la Formalización de la Informalidad) ${ }^{24}$, 127 millones de trabajadores se ubican en el sector informal.

Son al menos 35 millones de jóvenes que pueden ser víctimas de desaliento y frustración ante la persistente falta de oportunidades laborales, por ello los gobiernos deben considerar el empleo de los jóvenes como una prioridad nacional, es decir que los programas de políticas generales y planes nacionales de desarrollo deben contemplar políticas económicas y sociales coherentes que aborden el empleo juvenil y establezcan objetivos específicos.

Como una buena parte de la solución a este grave problema está en la educación de esos jóvenes, queda un gran campo abierto para la innovación en la educación, para atraer a esos jóvenes, valiéndose de un diseño funcional y atractivo de las instalaciones, de cursos cortos que los incorporen al sector formal de la economía y que estén en sintonía con la demanda laboral, de programas de pasantías en las 
que reciban un modesto salario, de cursos vía internet, de tecnologías audiovisuales que los motiven a asistir, en lugar de abandonar sus cursos.

La informalidad impide aprovechar el potencial de un sector fundamental de la economía donde abundan los emprendedores con iniciativa e ingenio, dispuestos al mayor esfuerzo si les brindan las oportunidades que la sociedad les debe.

\section{Conclusiones}

La novedad con la actual revolución tecnológica, donde las Tic e internet son la columna vertebral, es que también ha venido substituyendo el trabajo intelectual debido a la acción conjunta de los sistemas de informática con procesadores que presentan una creciente capacidad y han venido cumpliendo la ley de Moore; por otro lado, la situación se complica con programas y algoritmos cada vez más completos y sofisticados, que en muchas áreas o tareas superan con creces a los humanos. Los procesos automatizados y la robotización han desplazado a millones de trabajadores en las fábricas de todo el mundo en los últimos 30 años, mejorando al mismo tiempo los niveles de calidad y la confiabilidad en los tiempos de entrega.

En el sector de servicios esta tendencia se ha acentuado en la última década; ya habíamos sido testigos de la notable reducción de las agencias de viaje, debido a la amplia oferta de servicios por internet, a los cuales puede acceder el potencial viajero desde su casa u oficina. Luego fue surgiendo una amplia variedad de servicios que se ofrecen por internet y que se transmiten a través de archivos digitales, conformando una reñida competencia global: tal es el caso de la lectura y diagnóstico de imagenología médica (tomografía computarizada, fluoroscopía con escaneo, resonancia magnética, mamografía, gammagrafía ósea, radiografías y ecografía); del diagnóstico de otras pruebas médicas, como biopsias y citología; de la elaboración de declaraciones de impuesto sobre la renta; del diseño de planos de arquitectura e ingeniería en todas sus ramas; de programas que convierten resultados deportivos y datos financieros o de mercado en reportajes y noticias; de la traducción de documentos; de la redacción de informes sobre cualquier tema; de la fabricación de prototipos en pocas horas. Es necesario señalar que en todas las actividades de la pequeña muestra reseñada, los especialistas tienen a su disposición software y programas que les facilitaban su tarea, aumentando su productividad y reduciendo costos.

La relación educación-innovación queda resaltada por el hecho de que tanto los procesos automatizados y la robotización como el software, programas y algoritmos que hemos mencionado son generados por la innovación, la cual es producto de personas con un conjunto de habilidades, destrezas y conocimientos que son las más demandadas. Lamentablemente dichas innovaciones, con una frecuencia creciente, pasan a desempeñar tareas que antes eran ejecutadas por 
personas calificadas, formadas en instituciones educativas de prestigio, pero que siguen planes de estudio para la caduca realidad del siglo pasado.

La cruda realidad de las personas desplazadas es que pocas tienen la oportunidad de reciclar su educación, es decir de actualizar sus conocimientos. La mayoría asume trabajos rutinarios con menores salarios o se queda sin trabajo.

Creo que los países en desarrollo en general, y de América Latina en particular, se enfrentan a una situación que, a título de resumen, podría estar representada por la siguiente ecuación:

1. Educación deficiente, tal como quedó demostrado con los resultados de PISA y TIMSS.

2. Desproporcionado peso de los estudiantes en ciencias sociales como porcentaje de los estudiantes de educación universitaria, recursos que deberían estar siendo utilizados en la formación de profesiones afines con la ciencia, la tecnología y la innovación.

3. Acelerado cambio tecnológico donde la participación de nuestras instituciones educativas y de I\&D es prácticamente cero. Somos usuarios de tecnologías, no generadores.

4. En los países que trabajan en las fronteras del conocimiento, desde hace años se está llevando a cabo un proceso de automatización y robotización, que se inició en el sector manufacturero, con una notable reducción de puestos de trabajo y la consecuente alza de la productividad. La robotización también está alcanzando a países emergentes, con empresas tipo oDM (original design manufacturers), como Foxconn, que fabrica productos electrónicos por encargo y es el mayor fabricante a nivel mundial, ubicada en Shenzhen, China. Esta empresa tiene un programa de instalación de robots para substituir parte del millón de empleados que tiene en sus diferentes fábricas.

5. En una fase más avanzada del proceso, a través de software más inteligentes y algoritmos se están automatizando trabajos de cuello blanco, en los que se suponía era difícil esa substitución, tal como se comenta en el ensayo "The future of employment: How susceptible are jobs to computerisation?”, donde se concluye que el $47 \%$ del empleo total de Estados Unidos está en alto riesgo, lo que significa que dichas ocupaciones serán potencialmente automatizables en un número indeterminado de años, tal vez una o dos décadas.

6. La globalización se profundizará, habrá una mayor competencia global para productos, procesos y servicios. El significado de este proceso para la población joven de América Latina es que, adicional a su deficiente preparación (que solo incluye habilidades de alfabetización y aritmética, así como conocimientos científicos elementales, los aspectos básicos de las TIC, fundamentos financieros y nociones básicas de cultura general y educación cívica), su perfil no contempla atributos como la capacidad de identificar, analizar y evaluar situaciones, ideas 
e información con el fin de formular respuestas a los problemas; estos jóvenes se verán en la imperiosa necesidad de reciclar y actualizar sus conocimientos o quedar fuera del mercado. Los empresarios están exigiendo creatividad para imaginar y concebir nuevas formas innovadoras de abordar los problemas, responder a las preguntas o expresar significado a través de la aplicación, síntesis o reutilización del conocimiento; y también buena comunicación y espíritu de colaboración para trabajar en coordinación con otros y poder transmitir información o enfrentar los problemas. Las aptitudes como estas son esenciales para la fuerza laboral del siglo XXI ("New vision for education, unlocking the potential of technology", World Economic Forum 2015), donde ser capaz de evaluar críticamente y transmitir conocimiento, así como el trabajo en equipo, se ha convertido en la norma. El resultado para una parte de la población joven de América Latina es que seguirá ocupando los puestos de trabajo no automatizables del sector servicios de la economía; quienes no tengan las habilidades exigidas por este sector sufrirán el duro impacto del desempleo tecnológico o ingresarán en el mercado informal.

7. La clase dirigente de América Latina no ha interiorizado el sencillo mensaje que encierra el "Esquema de la relación entre educación, innovación y desarrollo", cuya base y punto de partida es la educación.

\section{Bibliografía}

"Economic Letter", Federal Reserve Bank of Dallas, May 2014, disponible en: http://www.dallasfed.org/research/eclett/

"Education to employment: Getting Europe's youth into work", McKinsey \& Company, disponible en: http://www.mckinsey.com/insights/social_sector/ converting_education_to_employment_in_europe

"El futuro de la productividad", oECD, disponible en: http://www.oecd.org/eco/ El-futuro-de-la-productividad.pdf

"Innovation Policy a Guide for Developing Countries", World Bank Institute, 2010, disponible en: https://openknowledge.worldbank.org/bitstream/han dle/10986/2460/548930puboepi11C10Dislosed061312010.pdf

"New vision for education, unlocking the potential of technology", World Economic Forum 2015, disponible en: http://www3.weforum.org/docs/wefuSA_NewVisionforEducation_Report2015.pdf

“OECD Skills Outlook 2013", disponible en: http://skills.oecd.org/skillsoutlook. html

“Tendencia Económica”, Informe Mensual de Fedesarrollo, mayo de 2011, disponible en: http://www.repository.fedesarrollo.org.co/handle/11445/611

"The competitiveness and innovative capacity of the United States", Department of Commerce, January 2012, disponible en: http://www.esa.doc.gov/reports/ competitiveness-and-innovative-capacity-united-states 
“The Global Information Technology Report 2015”, Networked Readiness Index (NRI), World Economic Forum (WEF), disponible en: http://reports.weforum. org/global-information-technology-report-2015/

"World Population Prospects - The 2015 Revision - Key Findings and Advance Tables", The Department of Economic and Social Affairs of the United Nations Secretariat, disponible en: http://esa.un.org/unpd/wpp/

A Policy Innovation, World Bank.

Autor, DAvid, "The polarization of job opportunities in the U.S. labor market implications for employment and earnings", April 2010, MIT Department of Economics, disponible en: http://economics.mit.edu/files/5554

CEPAL, "Cambio estructural para la igualdad, Una visión integrada del desarrollo", 2012, disponible en: http://www.cepal.org/pses34/noticias/ documentosdetrabajo/4/47424/2012-ses-34-cambio_estructural.pdf

CiA World Factbook, disponible en: https://www.cia.gov/library/publications/ the-world-factbook/

Frey, Carl B. y Michael A. Osborne, "The future of employment: How susceptible are jobs to computerisation?”, Universidad de Oxford, 2013, disponible en: http://www.oxfordmartin.ox.ac.uk/downloads/academic/ The_Future_of_Employment.pdf

http://timssandpirls.bc.edu/

Informe "Sistemas nacionales de ciencia, tecnología e innovación en América Latina y el Caribe", unesco, disponible en: http://unesdoc.unesco.org/ images/0018/001871/187122s.pdf

Maloney, William F., "Missed Opportunities, Innovation and Resource-Based Growth in Latin America", The World Bank, December 2002, disponible en: http://siteresources.worldbank.org/DEC/Resources/Missed0Opportu1wth0in0Latin0America.pdf

McAfee, Andrew, http://andrewmcafee.org/blog/

National Science Foundation, Science and Engineering Indicators, disponible en: http://www.nsf.gov/statistics/seind14/

OECD Skills Outlook 2013, OECD.

PISA 2012 Results: Creative Problem Solving, Secretary-General of the OECD, disponible en: http://www.oecd.org/pisa/keyfindings/pisa-2012-resultsvolume-v.htm

Pritchett, Lant y Nancy Birdsall, "Schooling is not education!", disponible en: http://www.cgdev.org/doc/full_text/CGDReports/3120290/schooling-is-noteducation.html

The Global Innovation Index (GII). 